Sotiropoulou S, Sciutto G, Tenorio AL, Mazurek J, Bonaduce I, Prati S, Mazzeo R, Schilling M, Colombini MP, 2018. Advanced analytical investigation on degradation markers in wall paintings. Microchemical Journal 139, 278-294.

DOI: 10.1016/j.microc.2018.03.007

The final published version is available online at: https://doi.org/10.1016/j.microc.2018.03.007

(C) 2018. This manuscript version is made available under the Creative Commons Attribution-NonCommercial-NoDerivs

(CC BY-NC-ND) 4.0 International License (http://creativecommons.org/licenses/by-nc-nd/4.0/)

\title{
Advanced analytical investigation on degradation markers in wall paintings
}

\author{
Sophia Sotiropoulou ${ }^{\mathrm{a}, *}$, Giorgia Sciutto ${ }^{\mathrm{b}}$, Anna Lluveras Tenorio ${ }^{\mathrm{c}}$, Joy Mazurek ${ }^{\mathrm{d}}$, Ilaria Bonaduce ${ }^{\mathrm{c}}$, Silvia Prati ${ }^{\mathrm{b}}$, \\ Rocco Mazzeo $^{\mathrm{b}}$, Michael Schilling ${ }^{\mathrm{d}}$, Maria Perla Colombini ${ }^{\mathrm{c}, \mathrm{e}}$ \\ a Ormylia Foundation, Art Diagnosis Centre, Ormylia 63071, Greece \\ b University of Bologna, Department of Chemistry “G. Ciamician", Ravenna Campus, 48121 Ravenna, Italy \\ c Department of Chemistry and Industrial Chemistry, University of Pisa, Italy \\ ' Getty Conservation Institute, 1200 Getty Center Drive, Suite 700, Los Angeles, CA 90049, USA \\ e CNR-ICVBC, Institute for the Conservation and Valorization of Cultural Heritage, Area della Ricerca di Firenze, 50019 Sesto Fiorentino, FI, Italy
}

Keywords:

Wall paintings degradation

Lime ground

Proteinaceous binding media

Micro-FTIR-ATR mapping

Evolved Gas Analysis Mass Spectrometry (EGA/

MS)

Gas Chromatography-Mass Spectrometry (GCMS)

\begin{abstract}
Understanding the original techniques in the creation of an artwork is a prerequisite for the selection of the most appropriate conservation method. This is particularly essential in wall paintings where control of potential agents of deterioration and efficient monitoring are limited due to the scale of the paintings and their exposure to uncontrollable environmental fluctuations. Analytical studies are increasingly focused on the investigation and study of degradation products of organic binders originally added in the paintings on a lime-based plaster ground.

In the framework of IPERION-CH (Integrated Platform for the European Research Infrastructure ON Cultural Heritage) project, a collaborative task is dedicated to obtain knowledge about original organic materials used in wall paintings by evaluating and comparing different innovative methodologies and conventional diagnostic techniques used for the investigation of markers related to alteration mechanisms and degradation products. The non-invasive and microsampling methodology is first optimized on well-defined models that have been designed to simulate different painting techniques with limewater and five organic binders in different relative proportions. Future investigations will focus on the application of the optimized methodology on archaeological samples.

In the present paper, preliminary results on a selected set of models, submitted in different stages of a wellestablished artificial ageing protocol, demonstrate the specific complementary input of each analytical technique included in the analytical approach (colour measurements, micro FTIR-ATR analyses in cross-sections, Evolved Gas Analysis-Mass Spectrometry and Gas Chromatography-Mass Spectrometry). The comparative evaluation and interpretation of the results is a step forward in the optimization of the approach and in relating the analytical findings detected on the analysed samples to the original compounds and the possible changes for each group of binders (proteins/gums) due to degradation or interaction depending on the pigment/metal ion present.
\end{abstract}

\section{Introduction}

Wall paintings are one of the oldest art expression, thanks to the durability of its substrate, and offer us a well-preserved testimony of different archaeological contents and contexts. Lime-based wall paintings cover a very long-standing uninterrupted tradition, through which we can attest some well-established technical achievements often attuned to novelties or particularities related to local workshops or stylistic trends. Due to the historical and artistic importance of wall paintings, in the last decades many scientific efforts have been devoted on the

\footnotetext{
* Corresponding author. sophiaso@iesl.forth.gr
}

development of analytical methods for their investigation. In particular, multi-technique strategies are nowadays well-established, providing fundamental knowledge on the materials and painting techniques, $[1,2]$. A first in situ investigation combining multispectral imaging and non-invasive spectroscopic analysis (commonly XRF and FTIR) provides a screening of the materials used as well as a preliminary understanding of degradation issues present. Then, micro-destructive analyses applied for the investigation of sample stratigraphies, such as elemental analysis through energy dispersive X-ray analysis in the scanning electron microscope (SEM-EDX) and complementary microRaman molecular analysis, allow an exhaustive description of pigment mixtures in paint layers. A combined application of microFTIR spectroscopy and chemical separation techniques gives an overview of the organic substances 
present in the painting. However, the comprehensive characterization of the organic substances used as binder either in fresh or in dry limebased plaster, still represent a crucial challenging issue in conservation science, [3-5]. This lack of understanding may be ascribable to different reasons. The organic substance is initially added in low binder-to-pigment ratio and it is exposed to weathering processes that depend on changing climatic conditions and to deterioration phenomena induced by interaction with the substrate materials or with environmental pollutants, [3,6-8]. The identification of aged binders even when present in very small proportion can be obtained by chromatographic techniques (GC-MS) coupled with statistical analysis (PCA), [9]. However, it is common that original binders are fully degraded and only altered residues of the original organic substances may be detected on historical wall paintings. The correlation of these alteration products with the existence of specific original organic matters is an analytical challenge, as any diagnostic signatures are usually irreversibly changed.

The formation mechanism of metal carboxylates as degradation product, starting from the autoxidation of the fatty content of binding media (such as egg yolk or drying oil), has been demonstrated in several studies, [10]. Additionally, there are few case studies found in literature, investigating the ageing process of a lipidic binder in extensively deteriorated panel [11] or wall [7] paintings, through which metal oxalates are considered as a final decay product related to the same mechanism. In these studies, FTIR Imaging techniques were employed on paint stratigraphies for the spatially resolved chemical speciation of the organic lipidic binder (drying oil), its de-esterification products (free fatty acids) and its decay products (metal oxalates and carboxylates). The characterization and spatial correlation of both carboxylates and oxalates within the paint stratigraphy provided a first indication suggesting the origin and possible association of these degradation products. However, it is still not clear whether metal oxalates occur as decay products exclusively by the gradual degradation of lipidic binders or if they can be also generated by the degradation of non-lipidic organic media. It is worth to note that the formation of oxalates may be also related to different degradation processes, associated with the presence of oxalic acid, correlated with microbiological activity [12].

A research project for the advancement of our knowledge on the use of organic binding media in ancient wall paintings is undertaken in the framework of IPERION CH Research actions.

In attempt to fill a gap still present in diagnostic studies, this research was focused on the comprehensive characterization of specific markers related to alteration mechanisms and degradation products, in order to obtain knowledge about the original organic materials used in wall paintings. Thus, an advanced analytical protocol was defined and applied for the identification of degradation products instead of the original materials, which may not be present in altered wall paintings.

Key aspects of the analytical approach is the evaluation, comparison and effort of improving the various methodologies with a final aim to develop strategies for selecting the most effective approaches to identify and monitor changes in organic materials encountered in cultural heritage wall paintings.

To this aim, a systematic study was carried out. Standard mockups were prepared in the laboratory using different types of ancient recipes and materials, and then submitted to the ageing protocol to reproduce the most common exposure conditions for wall paintings. Finally, samples from each of the mockups were collected and analysed with complementary spectroscopic and chromatographic techniques to disclose new information on: (i) degradation mechanisms related to original or restoration materials (ii) possible correlation of alteration products with the original organic material even when it is hardly detectable; (iii) possible factors that may trigger or boost the deterioration process during ageing, (iiii) the role of the alkalinity of lime $(\mathrm{OH})$ or of the reactivity of the metal ions of the pigments in the degradation processes of the system pigment-binder-lime ground.

In addition to the well-established methodology based on the complementary evaluation of microFTIR spectroscopic data and chromatographic analysis results obtained, Evolved Gas Analysis Mass Spectrometry (EGA/MS) was also applied on samples before and after accelerated ageing. Thus, mass spectrometric temperature-resolved information was obtained and it was possible to characterise the materials present, according to the products evolved from thermally induced reactions. The modification of the thermal behaviour of the material is related to the physico-chemical changes undergone by the materials while ageing. Understanding these changes is fundamental to interpret the results obtained by other techniques and to establish a reliable analytical protocol overcoming the problematic and drawbacks linked to the ageing of the material for the identification of highly degraded organic binders.

EGA/MS has been scarcely used in the literature to identify binders in samples from artworks. However, approaches based on analytical pyrolysis, DTMS and thermogravimetric techniques have been recently applied to the characterization of proteinaceous materials [13], organic residues in pottery [14], and to study the degradation phenomena of collagen in archaeological bones [15] and of proteinaceous binders in paint samples either laboratory prepared or from paintings and archaeological objects [16]. Results highlighted the promising potential of the techniques to evaluate the degradation phenomena occurring and to evaluate and characterise highly aged materials. In the present paper, the results obtained on samples containing proteinaceous based binders are presented and discussed, as a first part of the ongoing project. Indeed, proteins have been largely used in wall painting, as original materials as well as restoration materials in past conservation procedures. Nevertheless, little attention has been devoted to the characterization of the interaction between proteins and metal ions present in pigments, considering the entire system pigment-binder-lime ground and the role played by its alkalinity. The clarification of the behaviour of different proteinaceous binders, with or without a lipid fraction, should assist in a first step towards a broader understanding of the possible interactions between natural polymeric binders and pigments' metals, in general.

\section{Materials and methods}

\subsection{Model samples preparation}

In order to understand the alteration mechanisms and optimize a non-invasive and microsampling methodology, a set of mockups have been prepared. Five organic binders (lipid/protein or polysaccharide based) and four pigments (with chromophores based on metal ions of different reactivity): Fe (red ochre, labeled as "2"), $\mathrm{Pb}$ (red lead, labeled as "3"), Cu (malachite, labeled as "1") and Carbon black, labeled as "4" were selected and used for the preparation of the paint samples.

The paint model systems were prepared on a HERAKLITH (wood wool) support, $25 \mathrm{~mm}$ thick, covered with a lime mortar as follows:

- 1st layer (7-8 mm thick): slaked lime mixed with an inert material (fine quartz sand/pumice, 3:1) at a ratio $1: 3$

- 2nd layer (1 mm thick): pure slaked lime applied once the mortar was solid but not dry

The slaked lime used was aged ( $>30$ years).

The paint layers were applied on the freshly (after one week) dry lime ground layer that had not been fully carbonated. In order to simulate different painting techniques, each organic binder was used in three relative proportions: (i) limewater + a small amount of organic binder, (ii) organic binder at medium content, (iii) higher concentration of organic binder. For practical reasons it was not easy to quantify the pigment/medium ratio each time. Instead, for the execution of the patches with only organic binder, at medium (ii) and high (iii) content, after the completion of the patch (ii) the relative amount of the binder in the paint mixture was increased by adding portions of binder, in order to obtain a translucent layer. 
The panels have been prepared in duplicates, one set is left to be Naturally Aged (NA), while the measurements were carried out exclusively to the second set, at time T0 $\sim 5$ months after preparation and then at gradual stages of Accelerated Ageing (AA). The measurements taken at times $\mathrm{T} 3$ and $\mathrm{T} 5$ of artificial ageing were compared with the measurements taken before (at time T0) the artificial ageing of the panels.

The results presented here are referred to the first part of the research, which was focused on the models painted with three proteinaceous binders and the two red pigments (red ochre "2" and red lead "3"). The complete consideration of all binders and pigments involved in the prepared models will be the subject of a next publication. Each panel of dimensions $\sim 10 \times 6$ corresponds to a different binder, WP1 (Egg yolk/distilled water, 1:1), WP2 (fine gelatin powder/distilled water in the ratio 1:8.) and WP4 (egg white/distilled water, 2:1), while in WPO only lime water has been used as a binder, (showed in Fig. 1 and described in Table 1). In the panels with organic binder, comprised of 5 vertical sections, from the left to the right, the two first sections, labeled "i", were painted with limewater and a small amount of organic binder, the two next vertical sections, labeled "ii", were painted with a medium content of organic binder and the fifth vertical section, labeled "iii", was painted with a higher concentration of organic binder.

In order to simulate simple and complex stratigraphies, for each binder, over a first red ochre layer ("2") a layer of red lead (" 3 ") was applied on sections (i) and (ii). Therefore, in the patches "i2" and "ii2" the paint layer contains only red ochre while the patches "i3" and "ii3" are constituted of a first layer of red ochre over which a layer of red lead was applied. The vertical section with high amount of binder, labeled "iii 2" includes only a single - red ochre - paint layer (Fig. 1).

As, to the best of our knowledge, egg yolk has never been analysed using EGA/MS before. Commercial freeze-dried egg yolk has been analysed as a reference material in order to support the data interpretation of the model samples WP1, Freeze-dried egg yolk in powder was purchased by Bresciani S.r.l. (Milano, Italy).

The pigments used for the preparation of the models were purchased from KREMER Pigmente, the natural gelatin powder from Abio. gr, No 4877 and the eggs from the market (biological products). The
Table 1

Description of the set of samples considered in this paper, as shown in Fig. 1.

\begin{tabular}{lll}
\hline Binders & $\begin{array}{l}\text { Pigments } \\
\text { red ochre (2) and red lead (3) }\end{array}$ \\
\cline { 2 - 3 } & Red ochre & $\begin{array}{l}\text { 1st layer: red ochre } \\
\text { 2nd layer: red lead }\end{array}$ \\
\hline Binder 0 (limewater without any organic & WP0_2A & WP0_3A \\
binder) & & \\
Binder 1 (limewater + egg yolk, low content) & WP1i_2A & WP1i_3A \\
Binder 1 (egg yolk) & WP1ii_2A & WP1ii_3A \\
Binder 1 (egg yolk, high content) & WP1iii_2A & - \\
Binder 2 (limewater + gelatin, low content) & WP2i_2A & WP2i_3A \\
Binder 2 (gelatin) & WP2ii_2A & WP2ii_3A \\
Binder 2 (gelatin, high content) & WP2iii_2A & - \\
Binder 4 (limewater + egg white, low content) & WP4i_2A & WP4i_3A \\
Binder 4 (egg white) & WP4ii_2A & WP4ii_3A \\
Binder 4 (egg white, high content) & WP4iii_2A & - \\
\hline
\end{tabular}

chemical composition of the pigments was certified as, 40,020 French natural Ochre RTFLES, $\left(\mathrm{Fe}_{2} \mathrm{O}_{3}+\mathrm{SiO}_{2}+\mathrm{Al}_{2} \mathrm{O}_{3}\right)$ and 42,500 Red Lead, $\left(\mathrm{Pb}_{3} \mathrm{O}_{4}\right)$.

\subsection{Accelerated ageing}

A Light/Temperature/RH ageing protocol was applied using the Atlas Ci400 weatherometer: Irradiance of Xenon-arc Ci400 at $0.5 \mathrm{~W} / \mathrm{m}^{2}$ with an outer filter CIRA/soda lime and inner filter Type S borrosilicate to stop far UV-light; $\mathrm{RH} 60 \%$ and $\mathrm{T} 40{ }^{\circ} \mathrm{C}$. The impact of the accelerated ageing process was monitored with FTIR measurements applied in regular time intervals (T0: starting point of AA, 5 months after preparation of the models, T1: after $14 \mathrm{~d}$ of AA; T2: after $21 \mathrm{~d}$; T3: after $28 \mathrm{~d}$; T4: after $42 \mathrm{~d}$ and T5: after $47 \mathrm{~d}=1128 \mathrm{~h}$ ). At time T5, FTIR monitoring was showing significant modification in the analysed spectra of the proteinaceous binders justifying the necessity for comprehensive analysis and comparative evaluation of the results obtained with the different techniques. EGA/MS and FTIR analysis were also

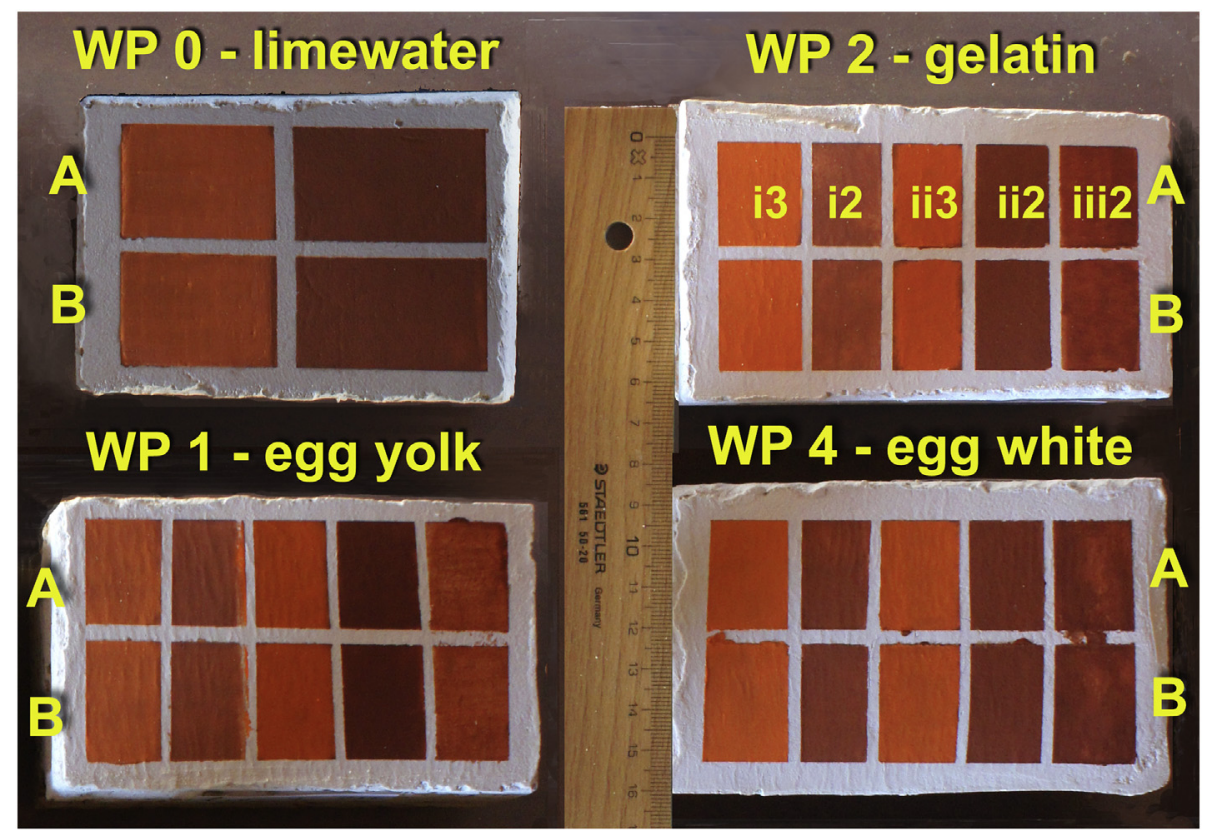

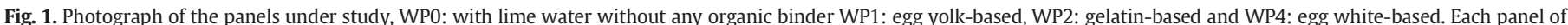

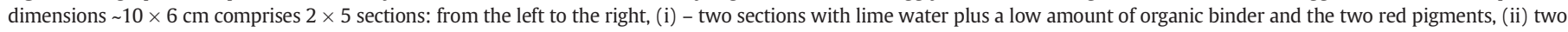

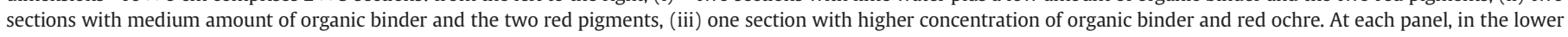
five-sectioned row (B), a mowilith layer was applied to simulate a consolidation procedure, but samples from this row will be the subject of future study. 
performed at an intermediate artificial ageing time (T3) in order to establish the evolution of the modifications occurring. After the assessment of the results presented in this work, further accelerated ageing will be applied in order to analyse the final degradation products of the observed going along mechanisms.

The weathering facility allows to accommodate the models in a rotating system, which assures equivalent exposure to the weathering conditions for all models. The selected protocol applying a RH/T and light ageing simultaneously refers to indoor artificial ageing exposure conditions and the main parameters to push is the Relative Humidity and Light (filtered in the far UV), keeping the temperature no higher than $40^{\circ} \mathrm{C}$.

\subsection{Noninvasive measurements on the paint surface}

Diffuse reflectance measurements in the visible have been carried out with a MINOLTA 2002 spectrophotometer possessing an integration sphere, with a spot size $\Phi 4 \mathrm{~mm}$.

\subsection{Optical microscope and micro FTIR-ATR mapping on cross-sections}

A Thermo Nicolet (Thermo Fisher Scientific, Waltham, MA, USA), iN ${ }^{\mathrm{TM}} 10 \mathrm{MX}$ imaging microscope, fitted with a mercury-cadmium-telluride (MCT) detector cooled by liquid nitrogen, was used for mapping analysis. The measurements were performed using a slide-on ATR objective, equipped with a conical germanium crystal, in the range $4000-675 \mathrm{~cm}^{-1}$, at a spectral resolution of $4 \mathrm{~cm}^{-1}$. A dedicated software, OMNIC Picta ${ }^{\mathrm{TM}}$ (Thermo Fisher Scientific, Waltham, MA, USA), was applied for a combined manipulation of the spectra dataset.

Cross-sections were prepared following the standard procedure, [8]. Briefly, the micro fragments were first embedded in $\mathrm{KBr}$ pellets. Afterwards, the pellet obtained was submitted to the polyester-resin embedding procedure. The double embedding system allowed to prevent the infiltration of the polyester resin into sample's porosities, avoiding contamination which may hamper the correct characterization of organic substances present within the samples. A dry polishing procedure was applied using Micro-Mesh ${ }^{\circledR}$ silicon carbide papers (Micro-Surface Finishing Inc., Wilton, USA) with successive grid from 2400 up to 12,000 .

Cross-sections were observed and documented stratigraphically by means of dark field observations performed with the use of an Olympus (Olympus Optical, Tokyo, Japan) BX51 microscope equipped with an Olympus DP70 digital scanner camera. A 100-W halogen projection lamp and an Ushio Electric (USHIO Inc., Tokyo, Japan) USH102D ultraviolet (UV) lamp were employed for the acquisition of visible and UV-fluorescence images, respectively.

\subsection{Evolved Gas Analysis Mass Spectrometry (EGA/MS)}

The EGA/MS instrumentation consists of a micro-furnace Multi-Shot Pyrolyzer EGA/Py-3030D (Frontier Lab) coupled with a gas chromatograph 6890 Agilent Technologies (Palo Alto, USA) equipped with a deactivated and uncoated stainless steel transfer tube (UADTM-2.5 N, 0.15 mm i.d. $\times 2.5$ m length, Frontier Lab). The GC was coupled with a 5973 Agilent Mass Selective Detector (Palo Alto, USA) single quadrupole mass. A program temperature was chosen for the micro-furnace chamber: initial temperature $50{ }^{\circ} \mathrm{C} ; 10{ }^{\circ} \mathrm{C} / \mathrm{min}$ up to $700{ }^{\circ} \mathrm{C}$. Analyses were performed under a helium flow $(1 \mathrm{ml} / \mathrm{min})$ with a split ratio $1: 20$. The micro-furnace interface temperature was kept at $100{ }^{\circ} \mathrm{C}$ higher than the furnace temperature until the maximum value of $300^{\circ} \mathrm{C}$. The inlet temperature was $280^{\circ} \mathrm{C}$. The chromatographic oven was kept at $300^{\circ} \mathrm{C}$. The mass spectrometer was operated in EI positive mode ( $70 \mathrm{eV}$, scanning $\mathrm{m} / \mathrm{z}$ 50-600). The MS transfer line temperature was $300^{\circ} \mathrm{C}$. The MS ion source temperature was kept at $230^{\circ} \mathrm{C}$ and the MS quadrupole temperature at $150^{\circ} \mathrm{C}$. Samples $(1 \mathrm{mg})$ were placed into a stainless steel cup and inserted into the micro-furnace. The sample underwent a thermal decomposition in inert atmosphere ( $\mathrm{He})$ over the chosen heating range, and evolved gaseous compounds were transferred to the mass spectrometer and directly ionized and analysed as a function of time.

\subsection{Gas Chromatography-Mass Spectrometry (GC-MS)}

An Agilent 6890N 5973 GC-MS was used for the identification of lipids and proteins. The samples were weighed (between 50 and 700 $\mu \mathrm{g}$ ) on a Cahn microbalance and are representative of typical wall painting samples' size. The samples fragmented easily and it was impossible to separate the paint from the ground layer. A sample was deposited into a high recovery crimp top vial and, subsequently, analysed by following three consecutive methods. First, it was tested for extractable components by adding ethanol:hexane $(1: 1)$ and heating to $60{ }^{\circ} \mathrm{C}$ for $1 \mathrm{~h}$. Next, it was injected into GC-MS with the following conditions. $25 \mathrm{M} \times 0.2 \mathrm{~mm} \times 0.2 \mu \mathrm{m}$ DB-5HT. Helium $1 \mathrm{ml} / \mathrm{min}$. Splitless injection $280{ }^{\circ} \mathrm{C}$. Transfer line $300{ }^{\circ} \mathrm{C}$. Oven $80^{\circ} \mathrm{C}(2 \mathrm{~min}), 10^{\circ} \mathrm{C} / \mathrm{min}$ to $340{ }^{\circ} \mathrm{C}$ (12 $\mathrm{min}) ; 20^{\circ} \mathrm{C} / \mathrm{min}$ to $360^{\circ} \mathrm{C}(5 \mathrm{~min})$. The sample was allowed to evaporate and Meth Prep II (a transesterification reagent) was added to the sample vial and heated to $60{ }^{\circ} \mathrm{C}$ for $1 \mathrm{~h}$ and injected into the GC-MS to identify any lipid components (see GC-MS conditions above). Lastly, the sample was hydrolysed (and amino acids reacted with ethyl chloroformate) and analysed in SCAN and SIM mode by GC-MS. The GC-MS conditions and method for amino acid analysis is described in detail and is based on seven "stable" amino acids: alanine, glycine, L-valine, L-leucine, L-isoleucine, L-proline, and L-hydroxyproline, [17]. The identification of proteins by GC-MS is accomplished by comparing the amino acids (building blocks of proteins) of each sample to those of standard reference materials using the method of correlation coefficients. A perfect match is a correlation coefficient of 1.0 , but for most samples 0.97 is an acceptable match.

\section{Results and discussion}

3.1. Visual examination and non-invasive measurements on the paint surface

Systematic measurements of diffuse reflectance in the visible range coupled with colorimetric measurements were carried out on the paint surface of the models to document the colour changes upon accelerated ageing, which in certain cases are clearly perceptible with the naked eye. Examining the visual appearance of the models (Fig. 1), there is not a clear distinction in colour or texture of the paint surface among the different binders. However, considering the workability of the paint during preparation, egg tempera (both WP1 and WP4) was smoother to spread and adhere on the ground compared to gelatin (WP2) which was not easy to homogenise and work, especially when added to the limewater (samples WP2i_xx).

The $L^{*} a^{*} b^{*}$ values (CIELAB 1976) for the samples before (at time T0) and at time T5 of AA as well as the respective calculated colour differences $\Delta \mathrm{E}$ are included in Table 2.

The most significant differences in colour ( $\Delta \mathrm{E}$ values indicated in red, in Table 2), which were also evident through comparative visual examination, refer to a considerable colour change from bright orange to dull brown for the samples of red lead, which applies for all mediums, included the lime water. In fact, the evaluation of the diffuse reflectance spectra in the visible allows to assess at a first immediate and non-destructive manner any modification at the pigment level. In the present study, it was attested that up to the considered stage of accelerated ageing (T5), there was not any structural change for red ochre. In the contrary, for red lead, the comparative evaluation of the spectra acquired on the red lead patches (T5 vs T0) (Fig. 2) suggests that the colour change is probably related to the pigment decomposition. Thus, it was possible to observe the attenuation of the $\mathrm{S}$ shaped reflectance with maximum at $630 \mathrm{~nm}$, characteristic of the $\mathrm{Pb}_{3} \mathrm{O}_{4}$ structure, and shift of the inflection 
Table 2

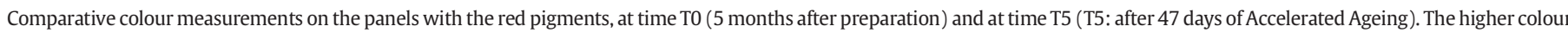
differences, indicated in bold, were measured on the colour patches with red lead.

\begin{tabular}{|c|c|c|c|c|c|c|c|c|c|c|c|}
\hline & $\mathrm{L}^{*}(\mathrm{D} 65)$ & $a^{*}(D 65)$ & $\mathrm{b}^{*}(\mathrm{D} 65)$ & & $\mathrm{L}^{*}(\mathrm{D} 65)$ & $a^{*}(D 65)$ & $\mathrm{b}^{*}(\mathrm{D} 65)$ & $\Delta \mathrm{L}^{*}$ & $\Delta \mathrm{a}^{*}$ & $\Delta \mathrm{b}^{*}$ & $\Delta \mathrm{E}$ \\
\hline WP1i_2A_T0 & 56.69 & 27.49 & 28.45 & WP1i_2A_T5 & 53.07 & 26.97 & 28.30 & -3.62 & -0.52 & -0.15 & 3.66 \\
\hline WP1ii_2A_T0 & 41.14 & 27.06 & 24.91 & WP1ii_2A_T5 & 42.93 & 24.20 & 22.44 & 1.79 & -2.86 & -2.47 & 4.18 \\
\hline WP1iii_2A_T0 & 61.74 & 30.12 & 35.66 & WP1iii_2A_T5 & 61.36 & 28.49 & 33.23 & -0.38 & -1.63 & -2.43 & 2.95 \\
\hline WP1i_3A_T0 & 62.95 & 34.60 & 38.76 & WP1i_3A_T5 & 58.23 & 21.86 & 29.16 & -4.72 & -12.74 & -9.60 & 16.64 \\
\hline WP1ii_3A_T0 & 56.65 & 40.11 & 51.79 & WP1ii_3A_T5 & 48.31 & 27.39 & 31.04 & -8.34 & -12.72 & -20.75 & 25.73 \\
\hline WP2i_2A_T0 & 57.51 & 26.81 & 28.45 & WP2i_2A_T5 & 55.76 & 25.82 & 27.51 & -1.75 & -0.99 & -0.94 & 2.22 \\
\hline WP2ii_2A_T0 & 45.85 & 25.49 & 26.25 & WP2ii_2A_T5 & 45.03 & 25.12 & 24.62 & -0.82 & -0.37 & -1.63 & 1.86 \\
\hline WP2iii_2A_T0 & 47.11 & 33.45 & 33.02 & WP2iii_2A_T5 & 47.75 & 29.22 & 28.28 & 0.64 & -4.23 & -4.74 & 6.39 \\
\hline WP2i_3A_T0 & 63.32 & 43.39 & 52.59 & WP2i_3A_T5 & 60.37 & 40.26 & 49.06 & -2.95 & -3.13 & -3.53 & 5.56 \\
\hline WP2ii_3A_T0 & 60.34 & 46.12 & 59.23 & WP2ii_3A_T5 & 49.78 & 30.36 & 35.55 & -10.56 & -15.76 & -23.68 & 30.34 \\
\hline WP4i_2A_T0 & 53.96 & 28.1 & 29.83 & WP4i_2A_T5 & 50.03 & 27.85 & 29.7 & -3.93 & -0.25 & -0.13 & 3.94 \\
\hline WP4ii_2A_T0 & 49.79 & 25.82 & 25.81 & WP4ii_2A_T5 & 47.5 & 25.09 & 25.77 & -2.29 & -0.73 & -0.04 & 2.40 \\
\hline WP4iii_2A_T0 & 55.34 & 30.17 & 30.48 & WP4iii_2A_T5 & 48.92 & 28.51 & 26.45 & -6.42 & -1.66 & -4.03 & 7.76 \\
\hline WP4i_3A_T0 & 59.85 & 36.63 & 44.51 & WP4i_3A_T5 & 58.17 & 33.88 & 41.05 & -1.68 & -2.75 & -3.46 & 4.73 \\
\hline WP4ii_3A_T0 & 58.16 & 37.88 & 43.83 & WP4ii_3A_T5 & 46.56 & 25.72 & 25.82 & -11.6 & -12.16 & -18.01 & 24.63 \\
\hline
\end{tabular}

point generally towards lower wavelengths (with the exception of the samples with WP4: egg white based binder that the inflection point shows a bathochromic shift, Fig. 2(d)). It is worthy to note that the observed colour change is more significant in the samples with higher organic binder content (samples 3ii) than the samples with lower content (samples 3i) or without any organic medium (sample WP0_3A). Red lead is known to be an unstable pigment in light, but also highly sensitive to humidity changes. The fading of red lead pigment in wall paintings and possible related degradation products have been extensively studied in model samples and real artworks, [18-22].

Although the three proteinaceous binders considered in this study presented differences in the workability of the paint, their behaviour during ageing proved to be dependent only on their chemical composition. Dissimilarities and detectable degradation products during the
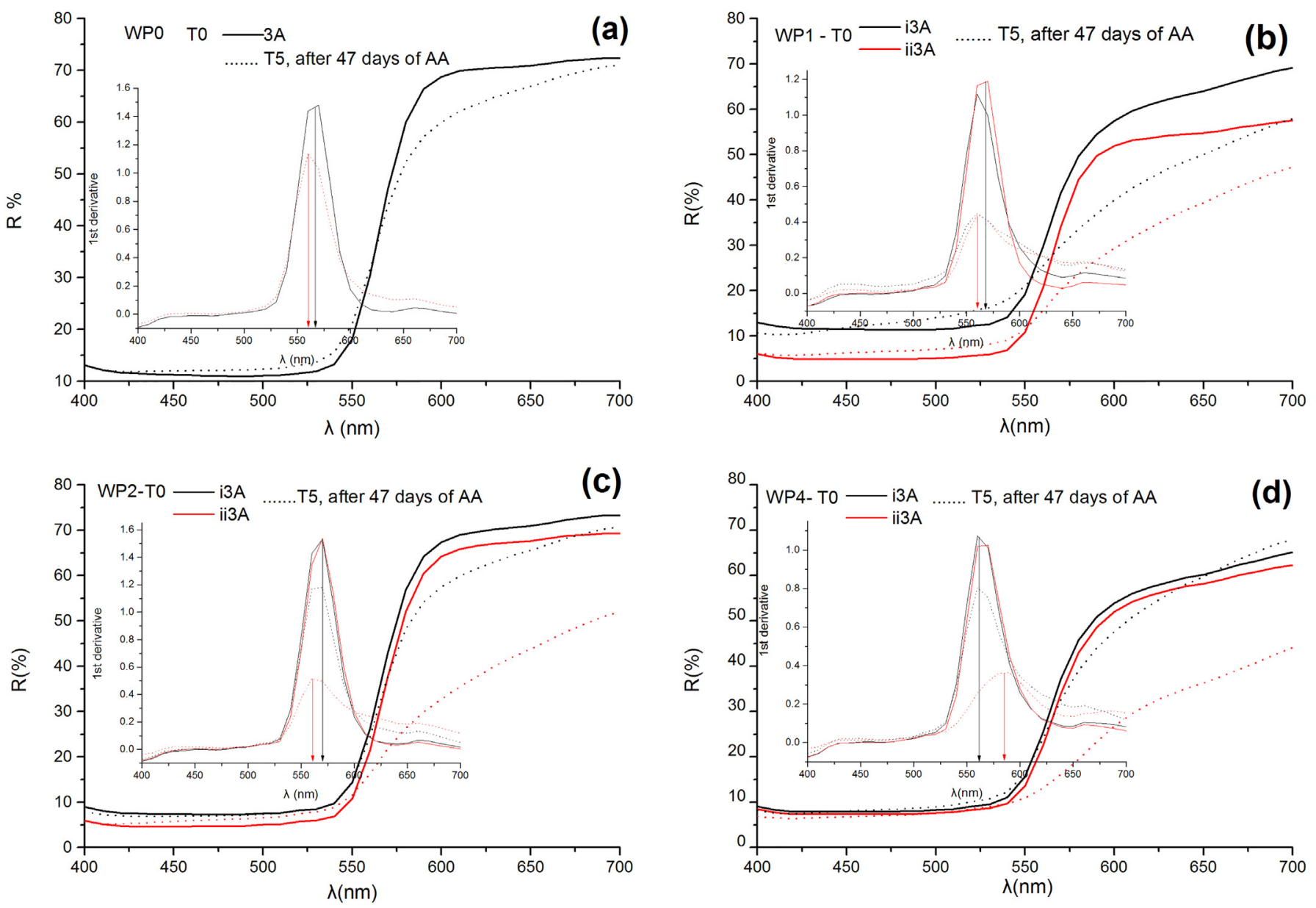

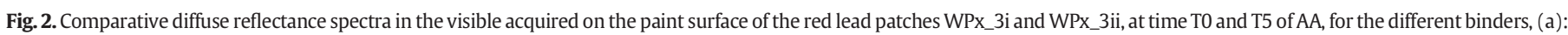
WP0 - lime water, (b) WP1- egg yolk based, (c): WP2-gelatin based and (d): WP4-egg white based. 
accelerated ageing seem to be mainly related to the lipidic content of the proteinaceous binder. Consequently, FTIR data on the egg white based samples (WP4xx) are not discussed as they did not disclose any additional information compared to those obtained on gelatin-based model samples (WP2xx). Equally, the discussion of the GC-MS results was based on the same binders, WP1 and WP2, as representative of the two types of proteinaceous media, lipidic (WP1) or pure (WP2).

\section{2. microFTIR-ATR mapping on paint cross-sections}

The analysis of paint cross-sections was aimed at characterizing the molecular composition of degradation markers, as well as their distribution within the paint stratigraphy. The importance of the spatial distribution of such components may represent a key tool in providing crucial information related to inter-correlation among components and degradation products. Thus, the analysis was aimed at offering a new insight into the correct description of degradation processes in proteinaceous based samples. Red samples containing red lead and/ or red ochre mixed with egg yolk or gelatin, submitted to the same ageing protocol for gradually longer time, were investigated and compared (Table 3).

\subsubsection{Egg yolk-based paints}

Two different types of samples containing egg yolk were investigated at different ageing times: WP1iii_2A and WP1ii_3A. The first was characterized by a single pigment layer applied on the lime ground, using a high content of binder. The molecular characterization of the paint stratigraphy allowed for the location of different components, according to the technique applied for the preparation of the paint models (Table 4). In more detail, calcium carbonate was identified as the principal component of the ground layer thanks to bands at $1400 \mathrm{~cm}^{-1}$ and $875 \mathrm{~cm}^{-1}$, ascribable to the $\mathrm{CO}_{3}^{2-}$ stretching and $\mathrm{CaCO}_{3}$ bending, respectively. Interestingly, calcium hydroxide $\left(\mathrm{Ca}(\mathrm{OH})_{2}\right)$ was also detected (see band at $3640 \mathrm{~cm}^{-1}$ ), suggesting its use as original component and indicating its incomplete carbonation. The use of a high content of binder, was clearly evident in the intense IR bands ascribable to the simultaneous presence of proteins and lipids in the paint layer. In particular, well defined bands were detected at $1644 \mathrm{~cm}^{-1}$ and $1538 \mathrm{~cm}^{-1}$ (attributed to $\mathrm{C}=\mathrm{O}$ stretching and $\mathrm{N}-\mathrm{H}$ bending, respectively), together with the carbonyl group at $1737 \mathrm{~cm}^{-1}$. The characteristic bands of $\mathrm{OH}$ stretching at $3690 \mathrm{~cm}^{-1}$ and the band at $1032 \mathrm{~cm}^{-1}$, suggested the presence of hydrated silicates.

After ageing, no evident changes were detected in the molecular composition of the ground layer, in which the presence of calcium hydroxide was still detectable. On the other hand, it was possible to observe significant modification of the spectral profile of the pigment layer. The carbonyl band became broader, probably due to the

Table 3

Description of the microsamples taken from the mockups painted with egg yolk (WP1) and gelatin (WP2) binders at different accelerated ageing stages, (T0, T3 and T5) and prepared in cross-section configuration to be analysed with FTIR-ATR mapping.

\begin{tabular}{lll}
\hline Binder & Red ochre (paint layer 1) & $\begin{array}{l}\text { Red ochre (paint layer 1) } \\
\text { Red lead (paint layer 2) }\end{array}$ \\
\hline Egg yolk & & $\begin{array}{l}\text { WP1ii_3A_T0 } \\
\text { WP1ii_3A_T3 } \\
\text { WP1ii_3A_T5 }\end{array}$ \\
Egg yolk (high content) & WP1iii_2A_T0 & \\
& WP1iii_2A_T3 & \\
Gelatin & WP1iii_2A_T5 & WP2ii_3A_T0 \\
& & WP2ii_3A_T3 \\
Gelatin (high content) & WP2iii_2A_T0 & WP2ii_3A_T5 \\
& WP2iii_2A_T3 & \\
& WP2ii_2A_T5 & \\
\hline
\end{tabular}

Table 4

FTIR-ATR mapping results on sample WP1iii_2A before (T0) and after accelerated ageing, (T5: after 47 days of AA). ${ }^{*}$ indicates new band after ageing: ${ }^{* *}$ indicates band modified after ageing.

\begin{tabular}{|c|c|c|c|c|}
\hline Layer & $\begin{array}{l}\text { Diagnostic FTIR } \\
\text { bands }\left(\mathrm{cm}^{-1}\right)\end{array}$ & Assignments & $\begin{array}{l}\text { Original } \\
\text { components }\end{array}$ & $\begin{array}{l}\text { Components } \\
\text { identified after } \\
\text { ageing }\end{array}$ \\
\hline $\begin{array}{l}\text { Ground } \\
\text { layer } \\
(0)\end{array}$ & $\begin{array}{l}3640 \\
1400 \\
875\end{array}$ & $\begin{array}{l}\mathrm{O}-\mathrm{H} \text { stretch } \\
\mathrm{CO}_{3} \text { stretch } \\
\mathrm{CaCO}_{3} \text { bend }\end{array}$ & $\begin{array}{l}\text { Calcium } \\
\text { hydroxide, } \\
\text { calcite }\end{array}$ & $\begin{array}{l}\text { Calcium hydroxide, } \\
\text { calcite }\end{array}$ \\
\hline $\begin{array}{l}\text { Paint } \\
\text { layer } \\
(1)\end{array}$ & $\begin{array}{l}1734^{* *} \text { broad } \\
\text { band } \\
1648 \\
1576^{*} \\
1538 \\
1410^{*} \\
1320^{*} \\
1031\end{array}$ & $\begin{array}{l}\mathrm{C}=\mathrm{O} \text { stretch } \\
\mathrm{C}=\mathrm{O} \text { stretch } \\
\mathrm{COO}^{-} \text {asym. } \\
\text { stretch } \\
\mathrm{COO}^{-} \text {asym. } \\
\text { stretch } \\
\mathrm{CO}_{3}^{2-} \text { stretch } \\
\mathrm{C}-\mathrm{O} \text { stretch } \\
\mathrm{Si}-\mathrm{O} \text { stretch }\end{array}$ & $\begin{array}{l}\text { Silicates, } \\
\text { proteins, lipids }\end{array}$ & $\begin{array}{l}\text { Silicates, proteins, } \\
\text { lipids } \\
\text { Calcite, } \\
\text { Calcium oxalates, } \\
\text { free fatty acids, } \\
\text { Ca carboxylates }\end{array}$ \\
\hline
\end{tabular}

triglyceride hydrolysis processes. Indeed, it is known that the degradation of egg tempera paintings may be mainly related to the fatty components with the formation of free fatty acids groups, [23]. This outcome corroborated the hypothesis that some pigments (such as the ironbased pigments) may promote the hydrolysis processes. It is worth noting that iron carboxylates were not detected, confirming the behavior of iron-based pigments in the degradation of egg paint films described in a previous paper [23]. Interestingly, after ageing, calcium carbonate seems to increase within the paint layer. This outcome is showed in Fig. S-1, by comparison of the false colour maps of the distribution of calcium carbonate in the paint layer of samples before (T0) and after (T5) accelerated ageing. However, this result will be further investigated in order to better describe the phenomena, which may be associated with the ongoing carbonation process.

Moreover, interaction between the organic binder and calcium salts occurred. Calcium carboxylates were clearly visible after ageing due to the presence of the diagnostic double bands at $1576 \mathrm{~cm}^{-1}$ and $1538 \mathrm{~cm}^{-1}$. Few studies report the identification of calcium carboxylates in egg or oil paint samples, [10]. FTIR-ATR chemical mapping performed on sample WP1iii_2A showed the distribution of calcium carboxylates overall the red pigment layer, Fig. 3d. The formation of calcium oxalates was observed in the upper part of the paint layer (Fig. 3e) based on the absorption band at $1320 \mathrm{~cm}^{-1}$ associated with the $\mathrm{COO}^{-}$ symmetric stretching mode (Fig. 3a). This distribution was probably induced by exposure of the paint layer, rich in binder, to artificial ageing. This evidence demonstrate the correlation between aged binder (characterized by the presence of a lipidic content) and the production of oxalates.

Sample WP1ii_3A showed a more complex paint stratigraphy compared to the previous described: over an egg yolk tempera layer with red ochre, applied on the ground, a second paint layer with red lead was applied (layer 2, Fig. 4c). In this case, a medium content of binder was used for both the red layers.

Red lead layer was characterized mainly by the presence of the typical spectral profile of egg binder due to the absence of absorption band of the pigment (lead oxide) in the Mid IR region. Moreover, traces of calcium carbonate were also identified (Table 5).

Ground and red ochre layers after ageing showed similar behaviour to those observed in the sample WP1iii_2A, indicating that there is no influence from the different amount of binder between the samples WP1iii_2A and WP1ii_3A. In particular, red ochre layer showed in both samples an increment in the relative amount of calcium carbonate (Fig. S-2) as well as the formation of the band at $1718 \mathrm{~cm}^{-1}$ ascribable to the presence of fatty acids groups produced by the triglyceride hydrolysis processes (Fig. 4d). Moreover, calcium carboxylates were also 


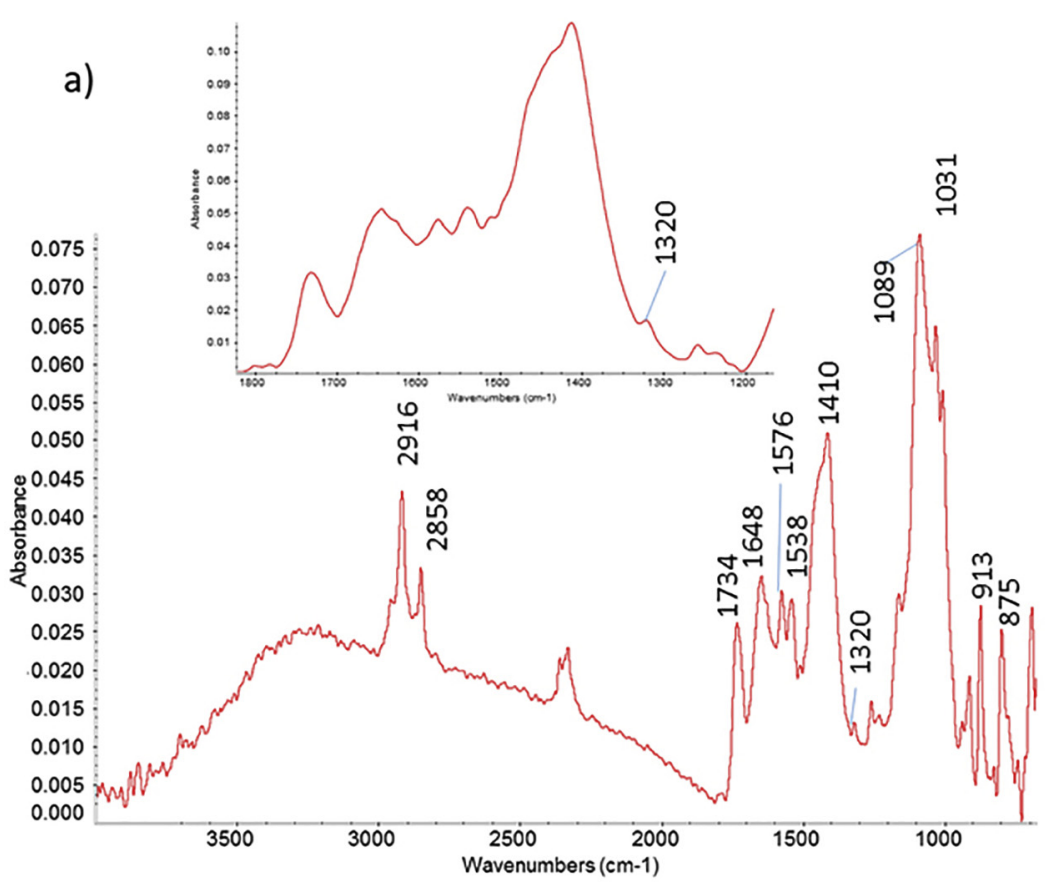

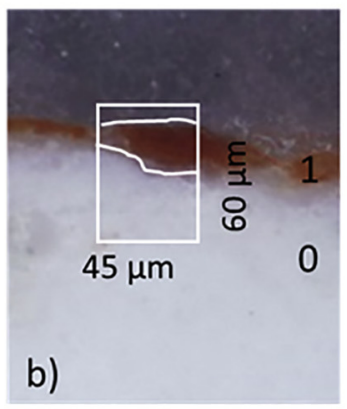
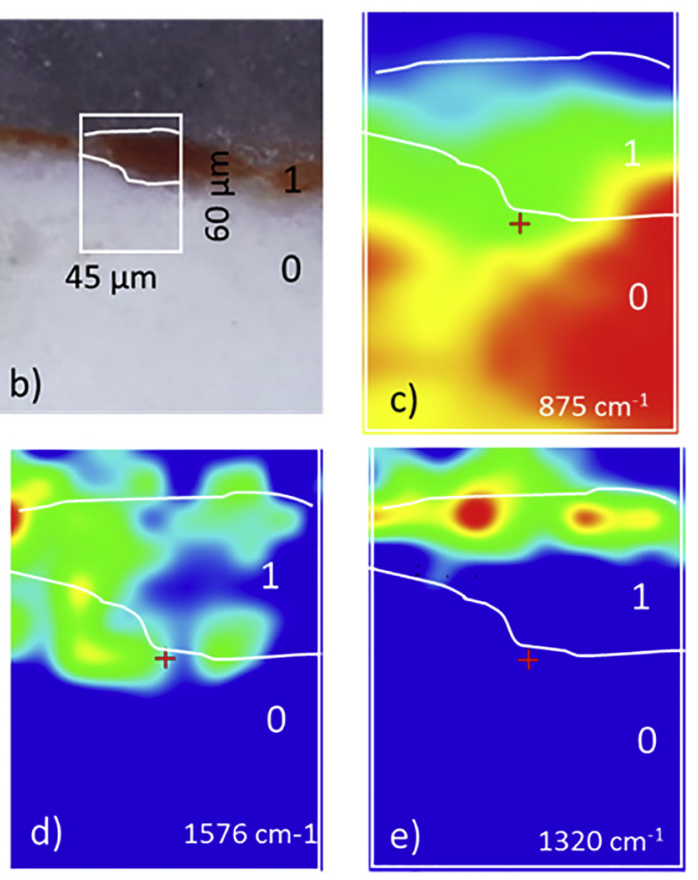

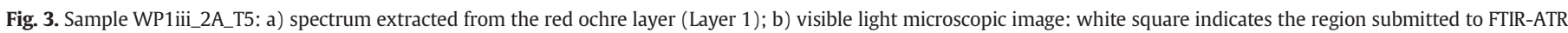

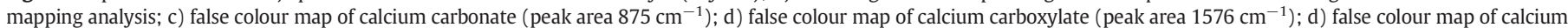
oxalates (peak area $1320 \mathrm{~cm}^{-1}$ ).

identified thanks to the presence of the diagnostic band at $1576 \mathrm{~cm}^{-1}$ (Fig. 4e). It was possible to clearly visualize the distribution of that band in the red ochre layer as well as in the upper part of the ground layer (Fig. 4d), formed probably due to the simultaneous presence of free fatty acids and a high concentration of calcium in these areas of the paint stratigraphy.

As already observed in model and real samples, lead ions are particularly prone to form metal carboxylates with material containing triglycerides $[7,23]$. Indeed, the presence of such degradation process was observed in the red lead layer of the aged sample WP1ii_3A_T5 thanks to the bands at 1542, 1563 and $1350 \mathrm{~cm}^{-1}$ (Fig. 4b), which may suggest the formation of neutral and/or basic form of lead acetates. However, it is worth to note that the identification of specific lead carboxylates can be difficult. Thus, usually two types of carboxylates species may be detected in aged oil paintings. The first is characterized by sharp bands associated with the crystalline metal complexes, while the second type is probably related to amorphous species and less ordered lead fatty acid salts characterized by much broader bands, often shifted from the band maximum of crystalline soap [24,25].

In layer 2, the intensity of the carbonyl band at $1730 \mathrm{~cm}^{-1}$ was reduced and almost totally replaced by the band at $1718 \mathrm{~cm}^{-1}$. This could be an indication that the production of free fatty acids and their conversion into lead carboxylates did not occur at the same rate. Calcium oxalates were detected, thanks to the band at $1320 \mathrm{~cm}^{-1}$ together with a shoulder at $1622 \mathrm{~cm}^{-1}$, ascribable to the $\mathrm{COO}^{-}$asymmetric stretching mode (Fig. 4b). Even though the intensity of these bands was weak, probably due to the small amount of product present, it was possible to clearly locate the oxalates in the upper part of the paint layer (Fig. 4g). In addition, traces of lead carbonate were also detected thanks to the band at $680 \mathrm{~cm}^{-1}$. The formation of lead carbonate in red lead pigment layers has been already described as the result of degradation phenomena in oil and egg-based paints [14].

\subsubsection{Gelatin-based paints}

Samples containing gelatin as a binder were submitted to the FTIRATR mapping analysis in the attempt to the better evaluate the spectral behaviour of proteinaceous materials with a limited or absent content of triglycerides.

The equivalent sample typologies, presenting one (WP2iii_2A) or two (WP2ii_3A) pigment layers were investigated.

In both of the samples the red ochre layer was characterized before ageing by the presence of the $\mathrm{C}=\mathrm{O}$ stretching (amide $\mathrm{I}$ ) and $\mathrm{N}-\mathrm{H}$ bending (amide II) absorption bands, ascribable to the proteinaceous binder. Moreover, hydrated silicates were clearly identified thanks to the $\mathrm{Si}-\mathrm{O}$ stretching and $\mathrm{O}-\mathrm{H}$ stretching bands at 1032 and $3690 \mathrm{~cm}^{-1}$, respectively. The analytical investigation of paint cross-sections after ageing did not highlight any significant modifications in the molecular composition of the red ochre and ground layer in sample WP2iii_2A (data not shown) or in sample WP2ii_3A (Table 6).

The red lead layer in the unaged sample WP2ii_3A, showed the characteristic spectral features of proteinaceous materials, together with the band at $1398 \mathrm{~cm}^{-1}$ related to the $\mathrm{CO}_{3}^{2-}$ stretching vibration. Bending modes at 875 and $680 \mathrm{~cm}^{-1}$ revealed the contemporary presence of calcium carbonate and of probably basic lead carbonate (Table 6), [26]. Traces of lead carbonate in unaged samples suggested a fast and initial conversion of the lead oxide into lead carbonate. Subsequently, the relative intensity of the diagnostic band at about $680 \mathrm{~cm}^{-1}$ increased with ageing, as well as the intensity of the $\mathrm{CO}_{3}^{2-}$ stretching band (Fig. 5). Moreover, the additional presence of the band at $3535 \mathrm{~cm}^{-1}$ suggested the formation of the lead carbonate hydroxide.

The literature reported some tentative explanations on the conversion mechanism of red lead into lead carbonate. This process was usually observed in oil or egg paints, due to the action of some acids, most likely derived from the organic binder or the environmental pollution (e.g. acetic acid), which reacts with lead to initially produce lead acetate and lead hydroxide. Subsequently such forms are converted into lead carbonate in the presence of carbon dioxide, [23]. The discussion regarding the origin of the altered phase has been the subject of research focused on the stability of red lead pigment in wall paintings, [20]. In that case, the authors ascribed the causes of the carbonation to the interaction of the paint layer with the atmospheric carbon dioxide, which lead to an increment of acidity of the surface. 

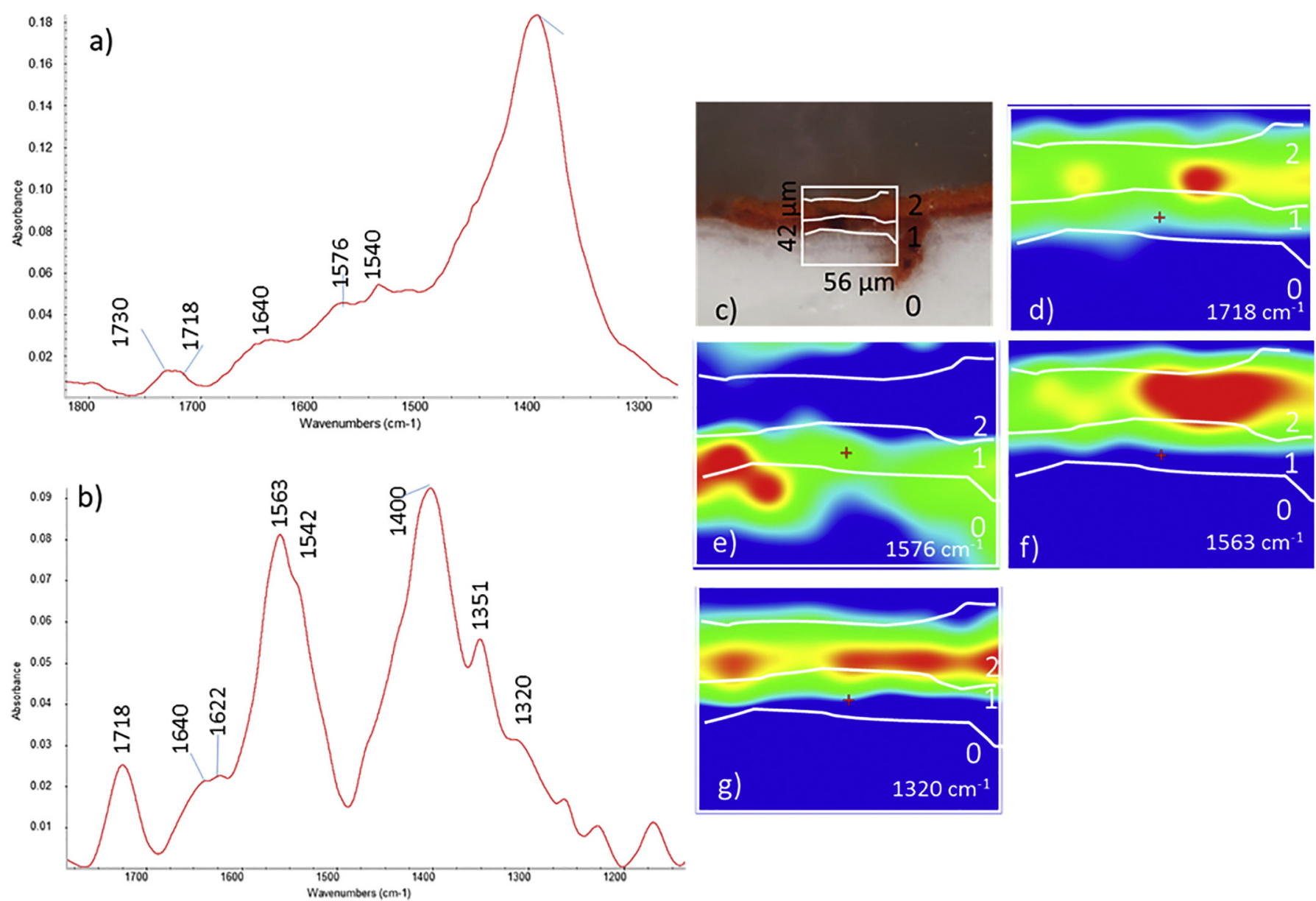

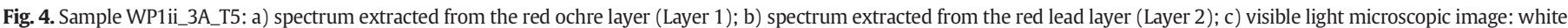

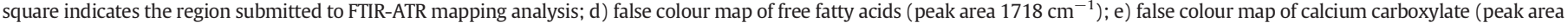
$1576 \mathrm{~cm}^{-1}$ ); f) false colour map of lead carboxylate (peak area $1563 \mathrm{~cm}^{-1}$ ); g) false colour map of calcium oxalates (peak area $1320 \mathrm{~cm}^{-1}$ ).

However, according to the data here presented, for the first time this conversion was undoubtedly observed in a pure protein (without any lipidic content) paint layer, opening the way to further investigation on the degradation process.

Finally, it was not possible to detect oxalates in any of the gelatinbased samples investigated. This outcome, in comparison with those observed in the egg-based samples, confirmed what already observed in real samples, [7]: the lipidic fraction in the binder may encourage the formation of metal oxalates.

\subsection{Analytical pyrolysis (EGA/MS)}

\subsubsection{Egg-based paints}

To the best of our knowledge, egg yolk has never before been analysed using EGA/MS. For this reason, in order to support the data interpretation of the samples described in Section 2.1 corresponding to WP1, freeze-dried egg yolk was first analysed as a reference material. The total ion thermogram (TIT) profile of freeze-dried egg yolk (Fig. 6 (a)) shows a profile that is substantially different from those obtained from purely proteinaceous binders shown in the literature [16]. Dried hen's egg yolk contains $65 \%$ of fats and $35 \%$ of proteins, differently to egg white that contains $98 \%$ of proteins and a $2 \%$ of fats. Egg glycerolipids consist of glycerides of unsaturated and saturated fatty acids that in hen's egg are as follows: $27 \%$ palmitic acid, $9 \%$ stearic acid, $44 \%$ oleic acid, $13 \%$ linoleic acid [27].
The TIT of egg white, mainly consisting of ovalbumin, was shown to present two non-well resolved peaks, ascribable to two main thermal degradation steps at $330{ }^{\circ} \mathrm{C}$ and $430{ }^{\circ} \mathrm{C}$, in agreement with the characteristic profile of a globulin protein [16] with an imidazole derivative, toluene, benzeneacetonitrile, phenol and indole, as well as nitrogencontaining cyclic compounds named diketopiperazines (DKPs) such as Cyclo (Pro-Leu), Cyclo(Pro-Ile) and Cyclo (Pro-Val), being the main pyrolysis products. The TIT of freeze-dried egg yolk instead, Fig. 6(a), shows an initial temperature range (A) between 200 and $250{ }^{\circ} \mathrm{C}$, followed by two well-resolved decomposition steps peaking at $310^{\circ} \mathrm{C}$ (C) and $410{ }^{\circ} \mathrm{C}(\mathrm{D})$, all of which show different average mass spectra. The $m / z$ of the compounds identified in the freeze-dried reference egg yolk and egg yolk based model samples (WP1iii) are summarised in Table 7.

The mass spectra (Fig. 6(b)) associated to the temperature range $A$ in Fig. 6(a) shows fragment ions that point to the presence of cholesterol $(m / z 353,368,386)$ [28]. The average mass spectra associated with the degradation steps B, C and D show the presence of masses related to the presence of a lipid material (Fig. 6(c), (d) and (e), respectively). The mass spectra associated to the main degradation step (C) shows the presence of fragment ions related to the EI ionisation of free fatty acids $(\mathrm{RCOOH})$, particularly the molecular ions $[\mathrm{M}]{ }^{{ }^{+}}$of palmitic, stearic and linoleic acids ( $m / z 256,284$ and 280), as well as the fragment ion $\left[\mathrm{M}-\mathrm{H}_{2} \mathrm{O}\right]^{\bullet}{ }^{+}$of oleic acid $(\mathrm{m} / \mathrm{z} 264) . \mathrm{m} / \mathrm{z} 264$ is also observed in the MS spectrum of linoleic acid. 
Table 5

FTIR-ATR mapping results on sample WP1ii_3A before (T0) and after accelerated ageing, (T5: after 47 days of AA). * indicates new band after ageing; ${ }^{* *}$ indicates band modified after ageing.

\begin{tabular}{|c|c|c|c|c|}
\hline Layer & $\begin{array}{l}\text { Diagnostic } \\
\text { FTIR bands } \\
\left(\mathrm{cm}^{-1}\right)\end{array}$ & Assignments & $\begin{array}{l}\text { Original } \\
\text { components }\end{array}$ & $\begin{array}{l}\text { Components identified } \\
\text { after ageing }\end{array}$ \\
\hline $\begin{array}{l}\text { Ground } \\
\text { layer } \\
(0)\end{array}$ & $\begin{array}{l}3640 \\
1400 \\
875\end{array}$ & $\begin{array}{l}\mathrm{O}-\mathrm{H} \text { stretch } \\
\mathrm{CO}_{3} \text { stretch } \\
\mathrm{CaCO}_{3} \text { bend }\end{array}$ & $\begin{array}{l}\text { Calcium } \\
\text { carbonate, } \\
\text { calcium } \\
\text { hydroxide }\end{array}$ & $\begin{array}{l}\text { Calcium carbonate, } \\
\text { calcium hydroxide }\end{array}$ \\
\hline $\begin{array}{l}\text { Paint } \\
\text { layer } \\
(1)\end{array}$ & $\begin{array}{l}3275 \\
3690 \\
1730^{* *} \\
\text { (broad) } \\
1718^{*} \\
1649^{* *} \\
\text { (shoulder) } \\
1574^{*} \\
1538^{* *} \\
1400 \\
1030\end{array}$ & $\begin{array}{l}\mathrm{N}-\mathrm{H} \text { stretch. } \\
\mathrm{O}-\mathrm{H} \text { stretch } \\
\mathrm{C}=\mathrm{O} \text { stretch } \\
\mathrm{COOH} \\
\text { Amide I } \\
\mathrm{COO}^{-} \text {asym. } \\
\text { stretch } \\
\mathrm{COO}^{-} \text {asym. } \\
\text { stretch } \\
\mathrm{CO}_{3} \text { stretch } \\
\mathrm{Si}-\mathrm{O} \text { stretch }\end{array}$ & $\begin{array}{l}\text { Silicates (ochre), } \\
\text { Calcium } \\
\text { carbonate } \\
\text { (traces) }\end{array}$ & $\begin{array}{l}\text { Proteins, lipids, silicates } \\
\text { (ochre), calcium } \\
\text { carbonate, free fatty } \\
\text { acids } \\
\text { Calcium carboxylates }\end{array}$ \\
\hline $\begin{array}{l}\text { Paint } \\
\text { layer } \\
(2)\end{array}$ & $\begin{array}{l}3275 \\
1718^{*} \\
1640^{* *} \\
\text { (shoulder) } \\
1563^{*} \\
1570^{*} \\
\text { (shoulder) } \\
1542^{* *} \\
1406 \\
1351^{*} \\
1320 / 1310\end{array}$ & $\begin{array}{l}\mathrm{N}-\mathrm{H} \text { stretch } \\
\mathrm{COOH} \\
\text { Amide } \mathrm{I} \\
\mathrm{COO}^{-} \text {asym. } \\
\text { stretch } \\
\mathrm{COO}^{-} \text {asym. } \\
\text { stretch } \\
\mathrm{COO}^{-} \text {asym. } \\
\text { stretch } \\
\mathrm{CO}_{3} \text { stretch } \\
\mathrm{COO} \text { stretch }\end{array}$ & $\begin{array}{l}\text { Proteins, lipids, } \\
\text { calcium } \\
\text { carbonate } \\
\text { (traces) Silicates } \\
\text { (traces) }\end{array}$ & $\begin{array}{l}\text { Proteins, lipids, Free } \\
\text { fatty acids, lead } \\
\text { carboxylates, calcium } \\
\text { and lead carbonate, } \\
\text { Calcium oxalates. }\end{array}$ \\
\hline
\end{tabular}

Peaks ascribable to the fragment ions RCOO ${ }^{+}(\mathrm{m} / \mathrm{z} 255,267,283$ and 321$)$ and $\mathrm{RCO}^{+}(\mathrm{m} / \mathrm{z} 239,267,264)$ were observed (Fig. 6(e)) in the mass spectra associated to the degradation step (D) in Fig. 6(a), and they are related to the thermal decomposition of acylglycerols, $[29,30]$.

The presence of fragment ions related to proteinaceous materials can be observed in the mass spectra obtained in the shoulder at $270{ }^{\circ} \mathrm{C}(\mathrm{B})$ and in the temperature range between 450 and $500{ }^{\circ} \mathrm{C}(\mathrm{E})$. The average mass spectrum related to the shoulder (B) shows the presence of $\mathrm{m} / \mathrm{z}$ 154 (Fig. 6(c)), which is a fragment ion encountered in the mass spectra of DKPs, probably related to the DKPs identified in the literature for egg white samples and specified in Table 7. In the mass spectra associated to the range $450-500{ }^{\circ} \mathrm{C}$ (Fig. $6(\mathrm{f})$ ), fragment ions related to oxygen and nitrogen containing aromatic compounds $(m / z 67,80,91,117,131)$ can be distinguished, to be ascribed to the decomposition of the more thermally stable portion of the polypeptide chain of the proteinaceous fraction of egg yolk.

The analysis of WP1iii_2A and WP1ii_3A samples containing red ochre and red lead pigments, based on Fe and $\mathrm{Pb}$ respectively, showed a similar behaviour while ageing. Fig. 7 shows the results obtained for WP1iii_2a and 3a (red ochre and red lead, respectively), which underwent several modifications during ageing.

Fe based samples (WP1iii_2A) showed the following behaviour:

a) The TIT profile (Fig. 7(a)) of the sample at time T0 shows two main degradation steps ( $C$ and D), similarly to the reference freeze-dried egg yolk analysed (Fig. 6) and related to the thermal decomposition of the glycerolipid component. Cholesterol is still present, evolved in the temperature range between 200 and $250{ }^{\circ} \mathrm{C}(\mathrm{A})$. The relative abundances of the degradation steps are however different with respect to the reference freeze-dried egg yolk analysed, indicating a different thermal behaviour.

b) At T3 (Fig. 7(c)), TIT shows four different not wellresolved degradation steps at 280 (step A), 324 (step B), 400 (step C) and 460 (step D) ${ }^{\circ} \mathrm{C}$. The mass spectra associated with steps $\mathrm{A}$ and $B$ show the characteristic fragment ions ascribable to heptadecanenitrile and octadecanenitrile [31] (Fig. 7(e)) while those associated to the steps $\mathrm{B}$ and $\mathrm{C}$ show the characteristic fragment ions $(m / z 67,91,117,131)$ of nitrogen and oxygen containing aromatic compounds, characteristic of the pyrolysis of proteins. Cholesterol is not present anymore. The mass spectra corresponding to the curve above $500{ }^{\circ} \mathrm{C}$ show the presence of $m / z 78$ and 128 , characteristic of aromatic molecules (benzene, naphthalene), which have been indicated as resulting from the pyrolysis of highly aggregated - crosslinked proteins (Fig. 7(f)), [16].

c) The TIT of T5 (Fig. 7(c)) shows little changes with respect to T3

The TIT curve of Pb containing samples (WP1ii_3a) at T0 (Fig. 7(b)) showed two main degradation steps $(\mathrm{A}$ and $\mathrm{B})$ : the mass spectra associated with the first one $\left(\mathrm{A}\right.$, peaking at $\left.303^{\circ} \mathrm{C}\right)$ show the characteristic fragment ions of heptadecanenitrile and octadecanenitrile (Fig. 7(e)), while those associated with the second peak (B, peaking at $450{ }^{\circ} \mathrm{C}$ ) show the characteristic fragment ions $(\mathrm{m} / z 67,91,117)$ of nitrogen and oxygen containing aromatic compounds, as well as $m / z 78$ and 128 , characteristic of aromatic hydrocarbons (benzene, naphthalene) (Fig. 7(f). Little differences are observed in the TIT curves of T3 and T5 (Fig. 7(d)) but for some changes in: a) the definition of two degradation

Table 6

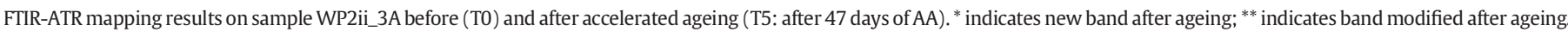

\begin{tabular}{|c|c|c|c|c|}
\hline Layer & $\begin{array}{l}\text { Diagnostic FTIR bands } \\
\left(\mathrm{cm}^{-1}\right)\end{array}$ & Assignments & Original components & Components identified after ageing \\
\hline Ground layer (0) & $\begin{array}{l}3637 \\
1400 \\
875\end{array}$ & $\begin{array}{l}\mathrm{O}-\mathrm{H} \text { stretch } \\
\mathrm{CO}_{3} \text { stretch } \\
\mathrm{CaCO}_{3} \text { bend }\end{array}$ & Calcium carbonate, calcium hydroxide & Calcium carbonate, calcium hydroxide \\
\hline $\begin{array}{l}\text { Red ochre paint layer } \\
\text { (1) }\end{array}$ & $\begin{array}{l}3686 \\
3613 \\
1643 \\
1546 \\
1404 \\
1027\end{array}$ & $\begin{array}{l}\mathrm{O}-\mathrm{H} \text { stretch } \\
\mathrm{O}-\mathrm{H} \text { stretch } \\
\text { Amide I } \\
\text { Amide II } \\
\mathrm{CO}_{3} \text { stretch } \\
\mathrm{Si}-\mathrm{O} \text { stretch }\end{array}$ & Silicates (ochre), Proteins, Calcium carbonate & Silicates (ochre), Proteins, Calcium carbonate \\
\hline $\begin{array}{l}\text { Red lead paint layer } \\
\text { (2) }\end{array}$ & $\begin{array}{l}3633 \\
3535^{*} \\
1650 \\
1554 \\
1395^{* *} \text { (higher intensity) } \\
1041 \\
683^{* *} \text { (higher intensity) }\end{array}$ & $\begin{array}{l}\mathrm{O}-\mathrm{H} \text { stretch } \\
\mathrm{O}-\mathrm{H} \text { stretch } \\
\text { Amide I } \\
\text { Amide II } \\
\mathrm{CO}_{3} \text { stretch } \\
\mathrm{Si}-\mathrm{O} \text { stretch } \\
\mathrm{PbCO}_{3} \text { bend }\end{array}$ & $\begin{array}{l}\text { Proteins, Calcium carbonate (traces), lead carbonate } \\
\text { (traces). }\end{array}$ & $\begin{array}{l}\text { Proteins, basic lead carbonate, Calcium carbonate } \\
\text { (traces) }\end{array}$ \\
\hline
\end{tabular}




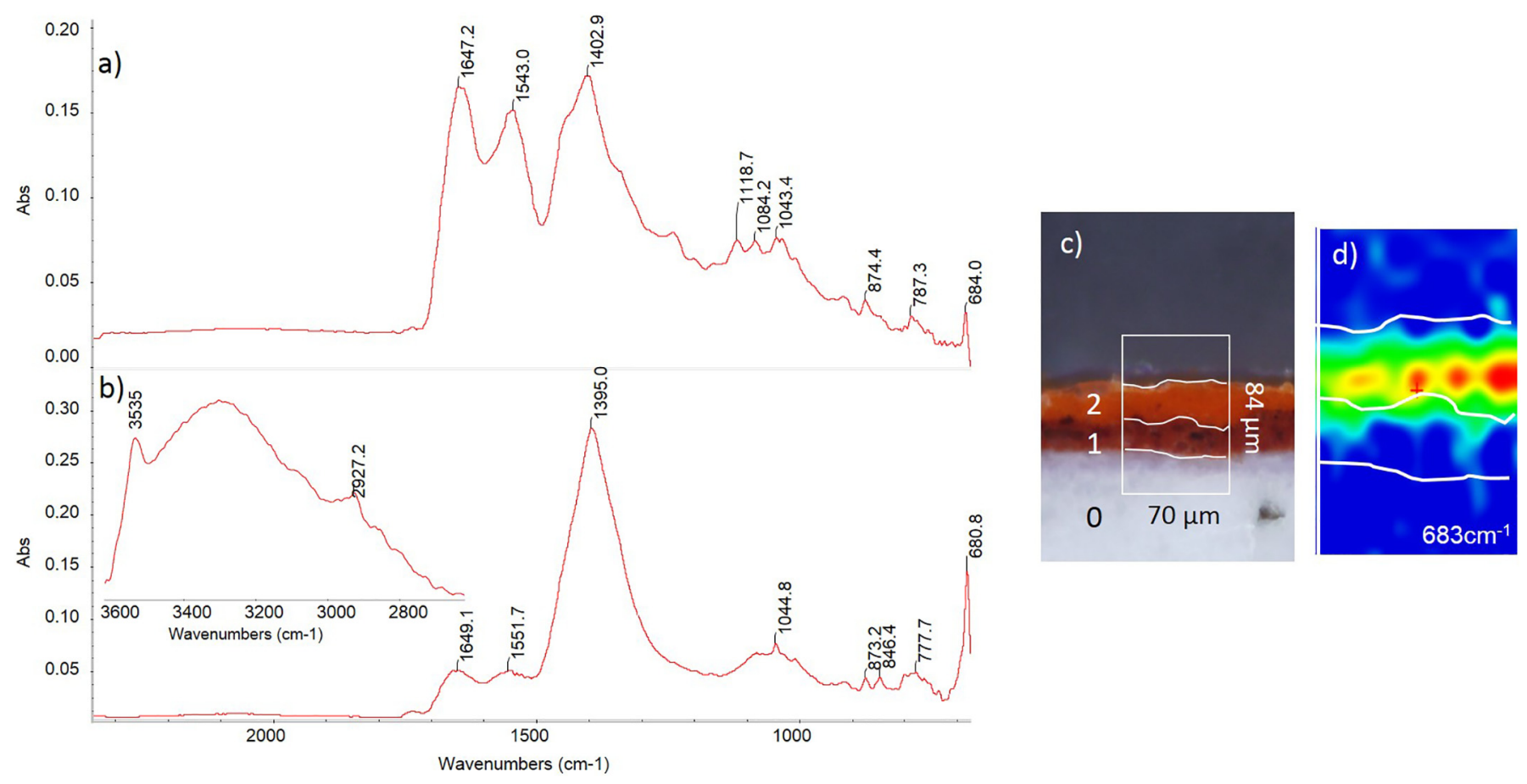

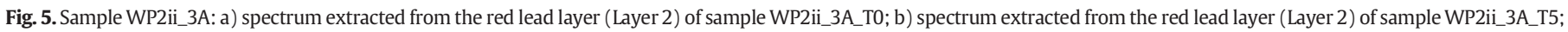
c) visible light microscopic image: white square indicates the region submitted to FTIR-ATR mapping analysis; $d$ ) false colour map of lead carbonate (peak area $683 \mathrm{~cm}^{-1}$ ).

steps ( $B$ and $C$ ) for the thermal degradation of the most thermally stable fraction of the protein and $\mathrm{b}$ ) the modification of the relative abundance of the thermal degradation steps showing a relative increase of the step leading to the evolution of heptadecanenitrile and octadecanenitrile with the ageing.

\subsubsection{Gelatin-based paints}

The paint model systems examined at time T0 (WP2iii_2A and WP2ii_3A) showed two non-well resolved peaks, ascribable to two main thermal degradation steps at $330{ }^{\circ} \mathrm{C}$ and $430{ }^{\circ} \mathrm{C}$ and a shoulder at $380^{\circ} \mathrm{C}$, in agreement with the degradation steps described in the literature for proteinaceous materials, in particular for animal glue [16]. The maximum temperature of the TIT corresponds to the first degradation step around $330{ }^{\circ} \mathrm{C}$. Fig. 8 shows the total ion thermogram (TIT) of the Fe based (WP2_iii_2A) and Pb based (WP2 ii_3A) samples at times T0, T3 and T5.

The average mass spectra corresponding to these degradation steps are also in agreement with those highlighted in the literature [16]. The mass spectra corresponding to the thermal degradation step centered at $330{ }^{\circ} \mathrm{C}$ (Fig. 8 (c)) showed the presence of $\mathrm{m} / z 70,111,124,154$, 186,170 and 210 - ascribable to DKPs - while $m / z$ 67, 91, 107 and 117 - ascribable to aromatic and nitrogen-containing aromatic compounds (pyrrole and alkyl-pyrrole, indole and alkyl-indole, phenol and alkylphenol, toluene, styrene and ethyl-cyanobenzene) - were observed in the mass spectra corresponding to the degradation step at $430{ }^{\circ} \mathrm{C}$ (Fig. $8(d)$ ). The identified proteinaceous DKPs and aromatic compounds are summarised in Table 8 . DKPs are formed upon heating by cyclisation of neighbouring amino acids in a polypeptide chain: diketopyrrole, cyclo (Pro-Gly), cyclo (Pro-Pro) and Cyclo (Pro-Hyp) are the most abundant DKPs produced by gelatine [16], in agreement with the amino acid composition of collagen, containing high amounts of proline and hydroxyproline. Aromatic and nitrogen-containing aromatic compounds are formed due to the thermal degradation of the lateral chains of some amino acids, as well as the pyrolysis of the more thermally stable portions of the protein [15]. Pyrrole is the most abundant aromatic compound produced by the thermal degradation of gelatin, [16].
Upon artificial ageing (T3 and T5 samples), the TIT curves of the samples showed a behaviour in agreement with the one observed for aged and degraded samples in the literature [14]. The TIT curve at time T3 (Fig. 8(a) and (b)) shows an increase of the relative abundance of the peak centered at $400{ }^{\circ} \mathrm{C}$ with respect to that at $330^{\circ} \mathrm{C}$. Samples at time T5 (Fig. 8(a) and (b)) doesn't show the degradation step at $330{ }^{\circ} \mathrm{C}$ related to the production of DKPs, and the TIT is dominated by a peak associated with the evolution of aromatic and nitrogen-containing compounds, which is shifted towards higher temperatures, with a maximum at around $430{ }^{\circ} \mathrm{C}$. A third non well-resolved peak centered at $460{ }^{\circ} \mathrm{C}$ is associated with mass spectra dominated by the presence of $m / z 78$, ascribable to benzene (WP2iii_2A-T3 and T5; WP2ii_3A_T5), as also observed for ancient and extremely degraded samples [16]. The average mass spectra of these peaks are provided in Fig. 8(e) and (f).

Fig. $8(\mathrm{~g})$ and $(\mathrm{h})$ show the extract ion chromatogram of the fragment ions monitoring the nitrogen and oxygen containing aromatic compounds $(m / z 91)$, the DKPs $(m / z 154,186)$ and pyrrole $(m / z 67)$ at times T0 and T5, relative to WP2iii_2A corresponding to Fe based pigmented (red ochre) paint layers. The curves highlight that - upon ageing - there is a decrease of the relative amounts of DKPs evolved from the sample, and the temperature at which aromatic molecules are evolved presents a maximum $50{ }^{\circ} \mathrm{C}$ towards higher temperatures.

\subsection{Quantitative Gas Chromatography-Mass Spectrometry (GC-MS) analysis}

Artificially aged (at time $\mathrm{T} 5=47$ days) model paint samples composed of gelatin (WP2) and egg yolk (WP1) with red ochre (pigment 2 ) or red ochre/red lead (pigments $2 / 3$ ) were analysed for any degradation products by GC-MS. The first step was solvent extraction to identify extractable degradation compounds. Next, Meth Prep II (a transesterification reagent) was used to identify lipids and other methylated compounds. Lastly, the samples were analysed in scan mode after hydrolysis and derivatization, to further identify degradation products as well as in SIM mode to quantify the stable amino acids and calculate the correlation coefficient to known reference proteins. 

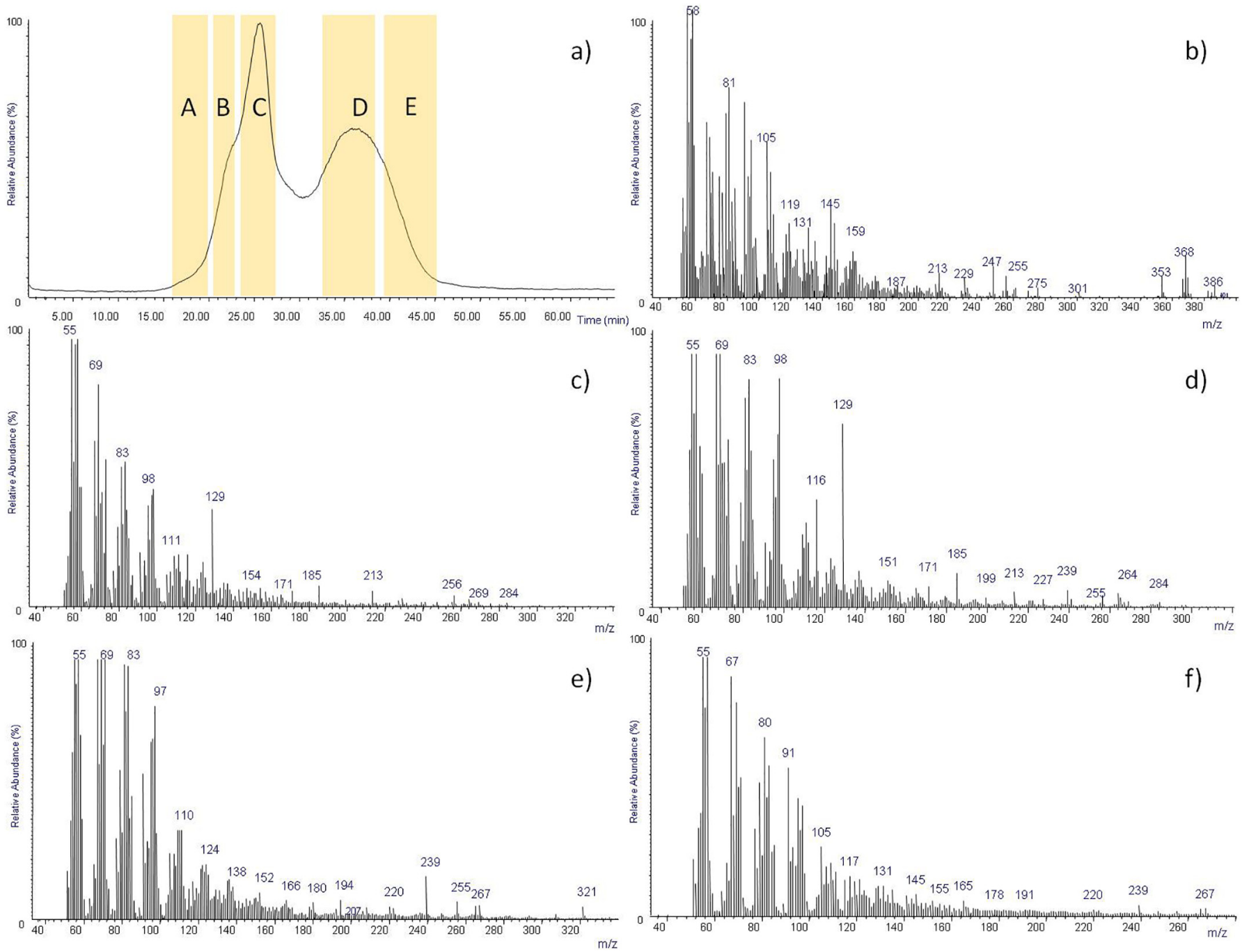

Fig. 6. (a) TIT of the freeze-dried egg yolk (b), (c), (d), (e), (f) average mass spectra of the temperature ranges indicated in panel (a) as areas A, B, C, D and E, respectively.

Table 7

Main DKPs and aromatic compounds identified in freeze-dried egg yolk and egg yolk based samples (WP1).

\begin{tabular}{|c|c|c|}
\hline & Compound & Mass spectra \\
\hline \multirow[t]{3}{*}{ DKPs } & Cyclo (Pro-Leu) & $70,86,125,154,(210)$ \\
\hline & Cyclo (Pro-Ile) & $70,86,125,154,(210)$ \\
\hline & Cyclo (Pro-Val) & $70,72,125,154,(196)$ \\
\hline \multirow{7}{*}{$\begin{array}{l}\text { Aromatic } \\
\text { compounds }\end{array}$} & Imidazole derivative & $123,138,151,166$ \\
\hline & Toluene & $51,65,91$ \\
\hline & Benzeneacetonitrile & $51,63,77,90,117$ \\
\hline & Phenole & $55,66,94$ \\
\hline & Indole & $89,90,91,117$ \\
\hline & Heptadecanonitrile & $\begin{array}{l}57,71,83,97,110,124,138,152,166,180, \\
194,208,222\end{array}$ \\
\hline & Octadecanonitrile & $\begin{array}{l}57,71,83,97,110,124,138,152,166,180 \\
194,208,222,236,264\end{array}$ \\
\hline \multirow[t]{7}{*}{ Lipid material } & Palmitic acid & $60,73,129,185,213,256$ \\
\hline & Stearic acid & $55,60,73,129,185,241,284$ \\
\hline & Oleic acid & $55,69,83,97,111,264,282$ \\
\hline & Linoleic acid & $55,67,81,95,110,280$ \\
\hline & $\begin{array}{l}{\left[\mathrm{CH}_{3}\left(\mathrm{CH}_{2}\right)_{\mathrm{n}} \mathrm{COO}^{+}\right]} \\
(\mathrm{n}=16,18)\end{array}$ & 255,283 \\
\hline & $\begin{array}{l}{\left[\mathrm{CH}_{3}\left(\mathrm{CH}_{2}\right)_{\mathrm{n}} \mathrm{CO}^{+}\right](\mathrm{n}} \\
=14,16)\end{array}$ & 239,267 \\
\hline & cholesterol & $\begin{array}{l}55,91,107,135,145,213,255,275,353 \\
368,386\end{array}$ \\
\hline
\end{tabular}

\subsubsection{Extraction with ethanol:hexane}

Extracts of the red ochre and red ochre/red lead egg yolk based samples (WP1i, WP1ii, and WP1iii 2A and 3A) contain free fatty acids from the egg lipid fraction (palmitic and stearic). Free palmitic and stearic acids were not detected in lime water (WPO 2A and 3A) or gelatin (WP2i, ii, and iii 2A and 3A) samples. Protein degradation products that are both low in molecular weight and soluble in ethanol and hexane were not observed in any of the samples with the methodology applied.

\subsubsection{Lipid analysis with Meth Prep II}

Red ochre and red ochre/red lead egg yolk samples (WP1i, ii and iii $2 \mathrm{~A}$ and $3 \mathrm{~A}$ ) contain fatty acid profiles similar to linseed oil. Palmitic $(P)$, stearic $(S)$, and azelaic $(A)$ acids ratios are used to distinguish between different types of drying oils. The yolk paint samples in this study had an A/P ratio equal to 1 or smaller and the $\mathrm{P} / \mathrm{S}$ ratio was found between 1.5 and 2.5, Table 9 . These results could be interpreted as a drying oil, as the lipid portion of the yolk closely resembles drying oils.

\subsubsection{Protein and amino acid analysis}

The analysed lime water paint model samples contain trace amounts of amino acids, WPO 2A (0.06\%) and WPO 3A (0.04\%). The amino acid profiles do not match any known reference proteins, but can be useful 

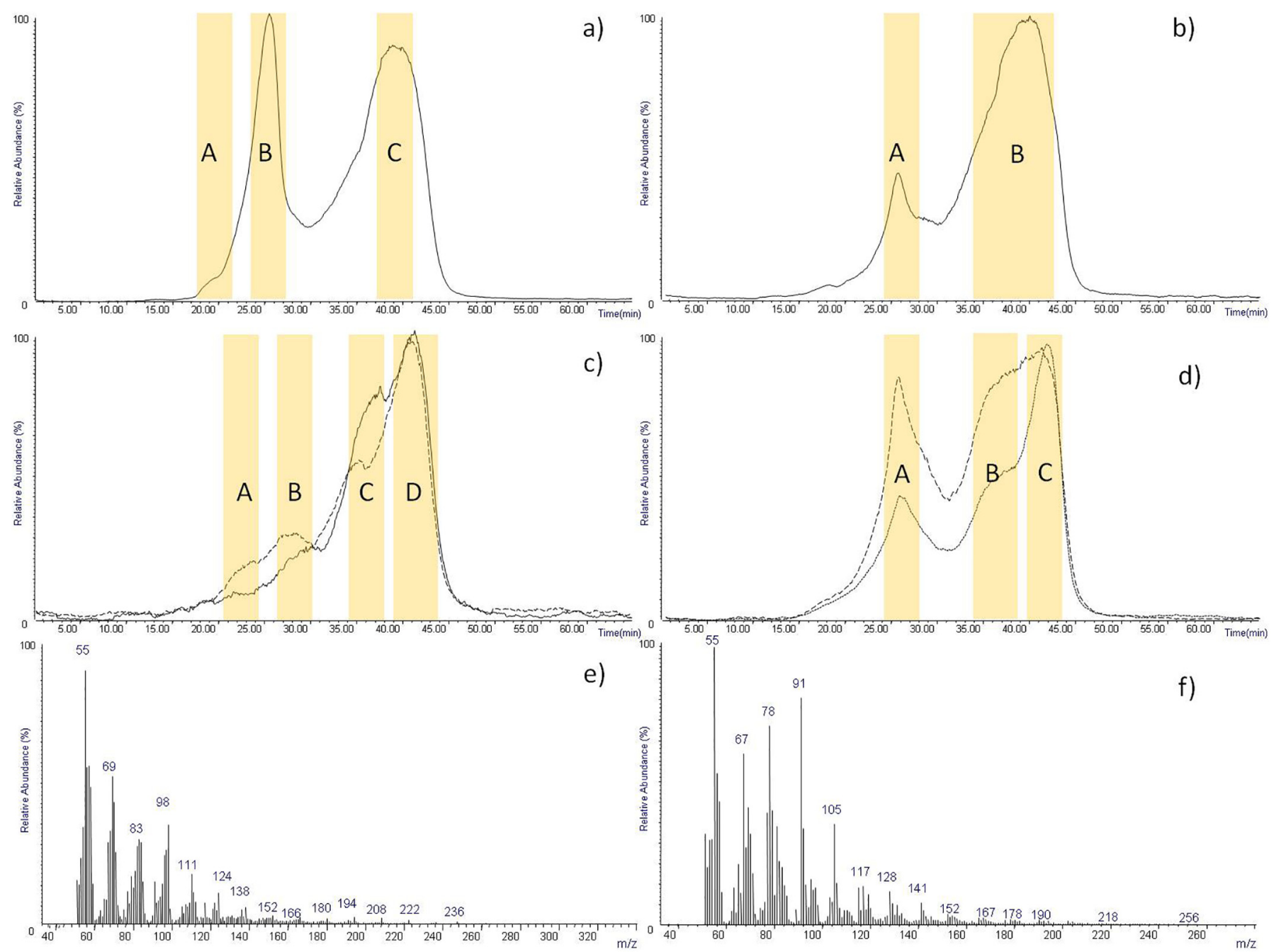

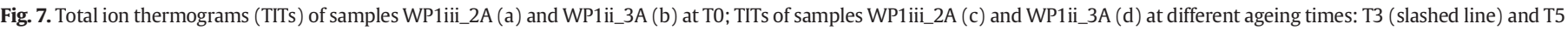
(dotted line); Average mass spectra associated to areas A (e) and B (f) in panel b.

as background blanks. WP1i, ii and iii 2A and 3A contain amino acids (between 0.4 and $1.6 \%$ ) that correlate to egg yolk. WP2i, ii, and iii contain amino acids (between 0.2 and $1.7 \%$ ) that correlate to gelatin. Results are summarised in Table 9.

Fig. 9 shows the percentage of each amino acid to the total amino acids found in the red ochre and red ochre/red lead samples tested (WP1i, ii, and iii 2A and 3A) after accelerated ageing at time T5. A sample of unaged whole egg without pigment is included for comparison. In all aged paint model samples, increased percentage of alanine, glycine, valine and leucine is observed, with corresponding decrease of phenylalanine and glutamic acids.

Fig. 10 shows the results of the gelatin-based model samples analysis of red ochre and red ochre/red lead paints (WP2i, ii and iii 2A and 3A), after accelerated ageing at time T5. Unaged gelatin without pigment is included for comparison. In all aged paint samples there is an increase in alanine, glycine, and proline, with a decrease in hydroxyproline. Even with this reduction of hydroxyproline, all of the samples tested showed a good match to gelatin, with a correlation coefficient of 0.98 to 0.99 , Table 9. GCMS chromatograms showed the differences between amino acids found in egg yolk and gelatin in red ochre and red lead paints, Fig. 11.

Even though amino acid degradation products are likely present, they were not easily identified by NIST library. Identification of degradation markers (SCAN mode) proved to be extremely difficult, as new peaks were observed but could not be identified because the NIST GCMS library did not match the new peaks identified in the amino acid SCAN analysis.

\subsection{Synthesis of the results}

Besides the individual value of novel results obtained with the different analytical methods employed in the present study, there are some general considerations that came out through a complementary interpretation of the data obtained, which may shed light on open questions about the degradation mechanisms in aged paint systems simulating ancient wall paintings. The comparative evaluation of the results obtained at progressive stages of accelerated ageing on the paint models with different proteinaceous binders, with or without a lipid fraction, provided some new data towards a broader understanding of the possible interactions that may occur during long term natural ageing between different polymeric binders and pigments' metals, in the paint systems of typical wall paintings configurations.

3.5.1. Identification of the nature of the original binder in the aged samples

GC-MS analysis is accepted as the most accurate approach for the identification of organic binders, in particular in the case of the widely use proteinaceous binders in the paintings on a lime mortar ground in plastered walls. However, the analytical performance and the accuracy 

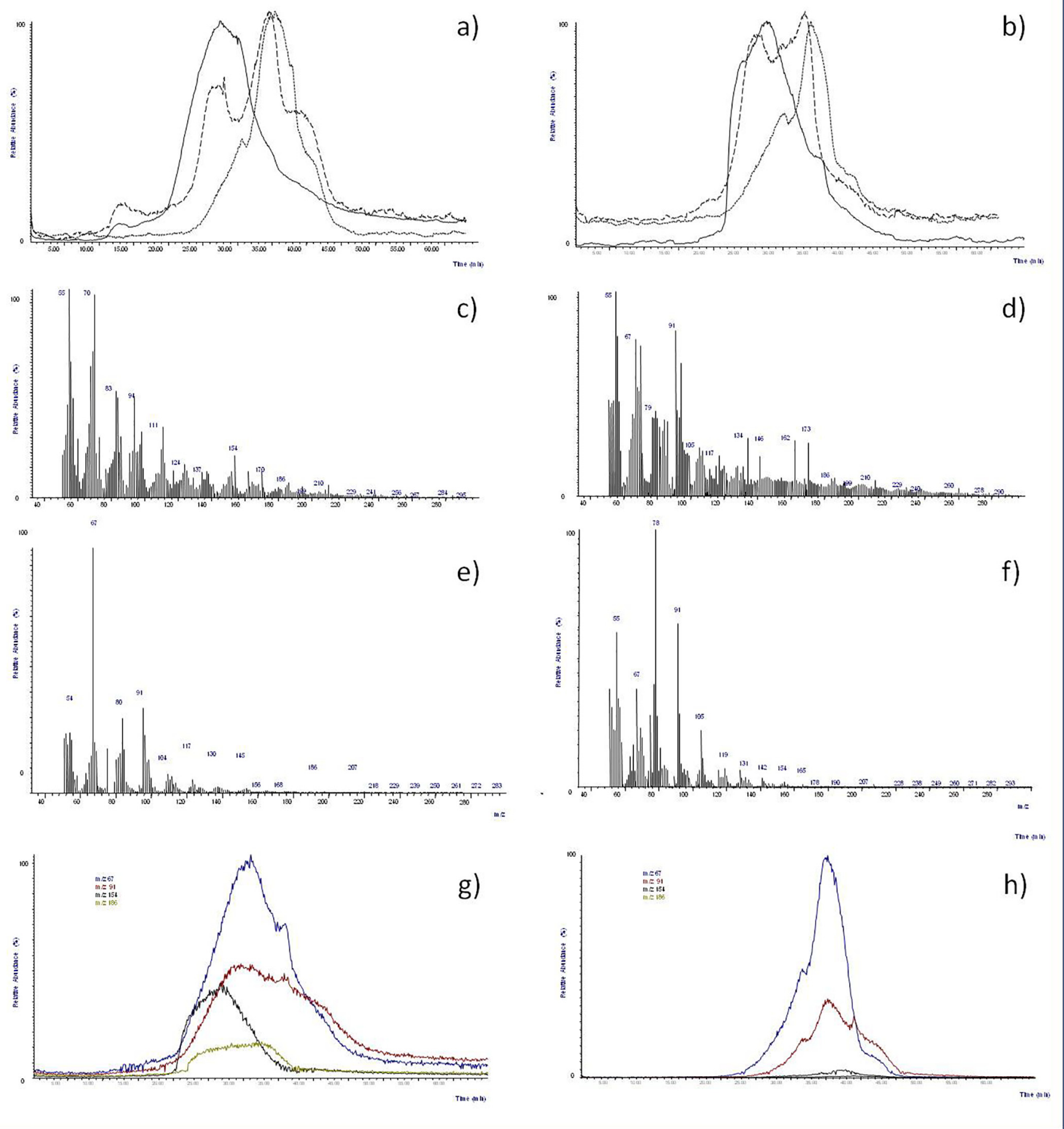

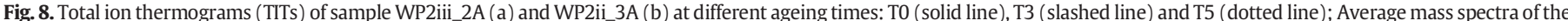

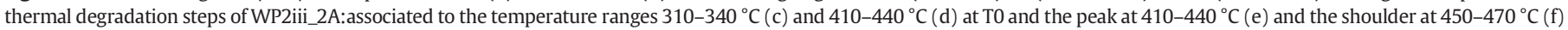
of the sample at T5. Extract ion thermograms of $m / z 67$ (pyrrole), $m / z 91$ (alkyl benzene), m/z 154 and 186 (DKPs), at times T0 (g) and T5 (h) of sample WP2iii_2A.

Table 8

Main DKPs and aromatic compounds identified in the gelatin-based paint samples WP2iii_2A and WP2ii_3A.

\begin{tabular}{lll}
\hline & Compound & Mass spectra \\
\hline DKPs & Cyclo (Pro-Gly) & $83,98,111,154$ \\
& Cyclo (Pro-Pro) & $70,96,138,166,194$ \\
& Cyclo (Pro-Hyp) & $70,86,124,210$ \\
Aromatic compounds & Diketodipyrrole & $65,93,130,186$ \\
& Pyrrole & 52,67
\end{tabular}

of the results in the exact identification of the original binder may be affected by the nature of the degradation mechanisms between pigment metal ions and the binder. The rate and products of these degradation mechanisms also depend on the amount of the proteinaceous substance originally added to the paint as a sole binding medium or to strengthen the binding power of limewater.

In the GC-MS analysis of gelatin - based model samples, WP2xx, it has been shown that in the aged samples with both pigments considered (red ochre and red lead), there is a considerable decrease of the 
Table 9

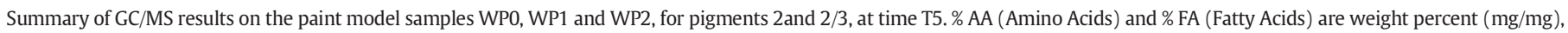
where ND = not detected. The correlation to egg and gelatin are reported, as well as Palmitic (P), Stearic (S), and Azelaic (A) acid ratios.

\begin{tabular}{|c|c|c|c|c|c|c|c|}
\hline Sample & \%AA & $\% \mathrm{FA}$ & Binder & Pigment & Correlation to whole egg & Correlation to gelatin & Comments \\
\hline WP0_2A & 0.06 & ND & Limewater & Red Ochre & 0.49 & 0.83 & \\
\hline WP0_3A & 0.04 & ND & Limewater & Red Ochre and Red Lead & 0.61 & 0.85 & \\
\hline WP1i_2A & 0.8 & 0.6 & Egg yolk & Red Ochre & 0.98 & 0.22 & $\mathrm{P} / \mathrm{S} 1.7 \mathrm{~A} / \mathrm{P} 0.8$ \\
\hline WP1i_3A & 0.4 & 0.4 & Egg yolk & Red Ochre and Red Lead & 0.97 & 0.25 & $\mathrm{P} / \mathrm{S} 2.2 \mathrm{~A} / \mathrm{P} 1.0$ \\
\hline WP1ii_2A & 0.8 & 0.4 & Egg yolk & Red Ochre & 0.99 & 0.14 & $\mathrm{P} / \mathrm{S} 2.3 \mathrm{~A} / \mathrm{P} 0.4$ \\
\hline WP1ii_3A & 1.6 & 1.1 & Egg yolk & Red Ochre and Red Lead & 0.99 & 0.28 & $\mathrm{P} / \mathrm{S} 2.2 \mathrm{~A} / \mathrm{P} 0.7$ \\
\hline WP1iii_2A & 1.1 & 0.6 & Egg yolk & Red Ochre & 0.97 & 0.27 & $\mathrm{P} / \mathrm{S} 2.3 \mathrm{~A} / \mathrm{P} 0.4$ \\
\hline WP2i_2A & 0.2 & ND & Gelatin & Red Ochre & 0.28 & 0.99 & \\
\hline WP2i_3A & 0.7 & ND & Gelatin & Red Ochre and Red Lead & 0.24 & 0.99 & \\
\hline WP2ii_2A & 0.8 & ND & Gelatin & Red Ochre & 0.09 & 0.99 & \\
\hline WP2ii_3A & 1.7 & ND & Gelatin & Red Ochre and Red Lead & 0.11 & 0.99 & \\
\hline WP2iii_2A & 1.4 & ND & Gelatin & Red Ochre & 0.12 & 0.99 & \\
\hline
\end{tabular}

relative amounts of hydroxyproline, the amino acid which is generally accepted as the characteristic marker for the identification of animal glues. Hydroxyproline is highly reactive and can turn to alanine, aspartic acid and glutamic acid (and other amino acids). Oxidative degradation of collagen is catalyzed by metals, [32] and different amino acids can be formed with ageing, [33]. All amino acids are subject to oxidation, but at different rates. Serine, threonine, proline, and hydroxyproline are rapidly oxidized while glycine is less prone to oxidation due to a lack of functional group, [34]. The derivatization procedure using ethyl chloroformate (ECF) can be problematic in the presence of ochre and red lead as the unstable amino acids such as aspartic acid, glutamic acid, serine and threonine are negatively impacted during hydrolysis and derivatization, with the consequence, in this case, the ineffective recovery of the amino acids, [17]. However, even with the observed

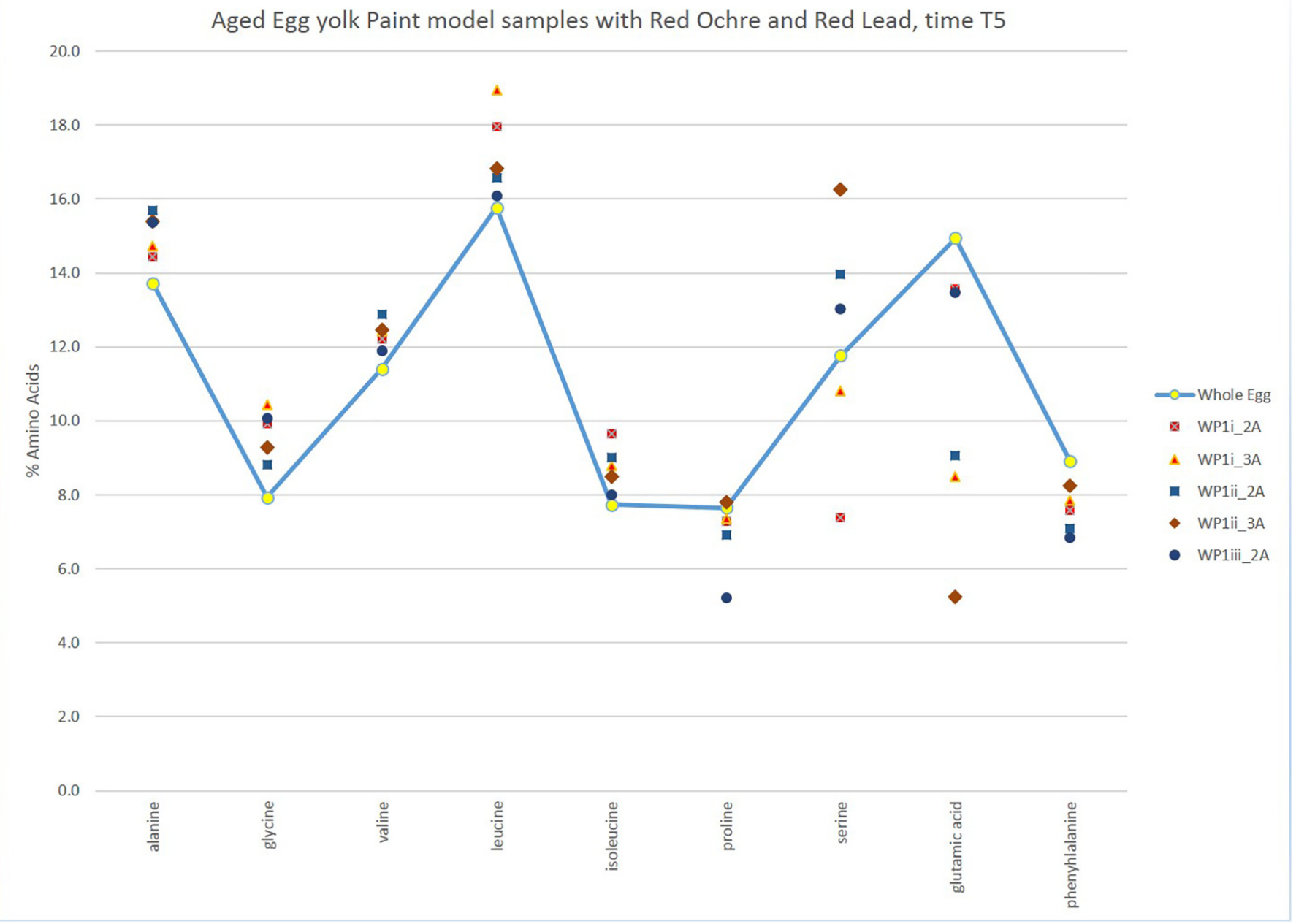

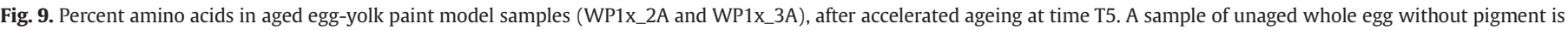

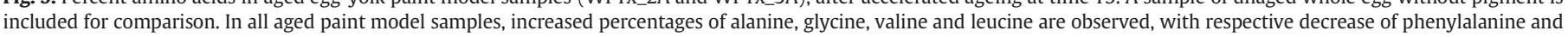
glutamic acids. 


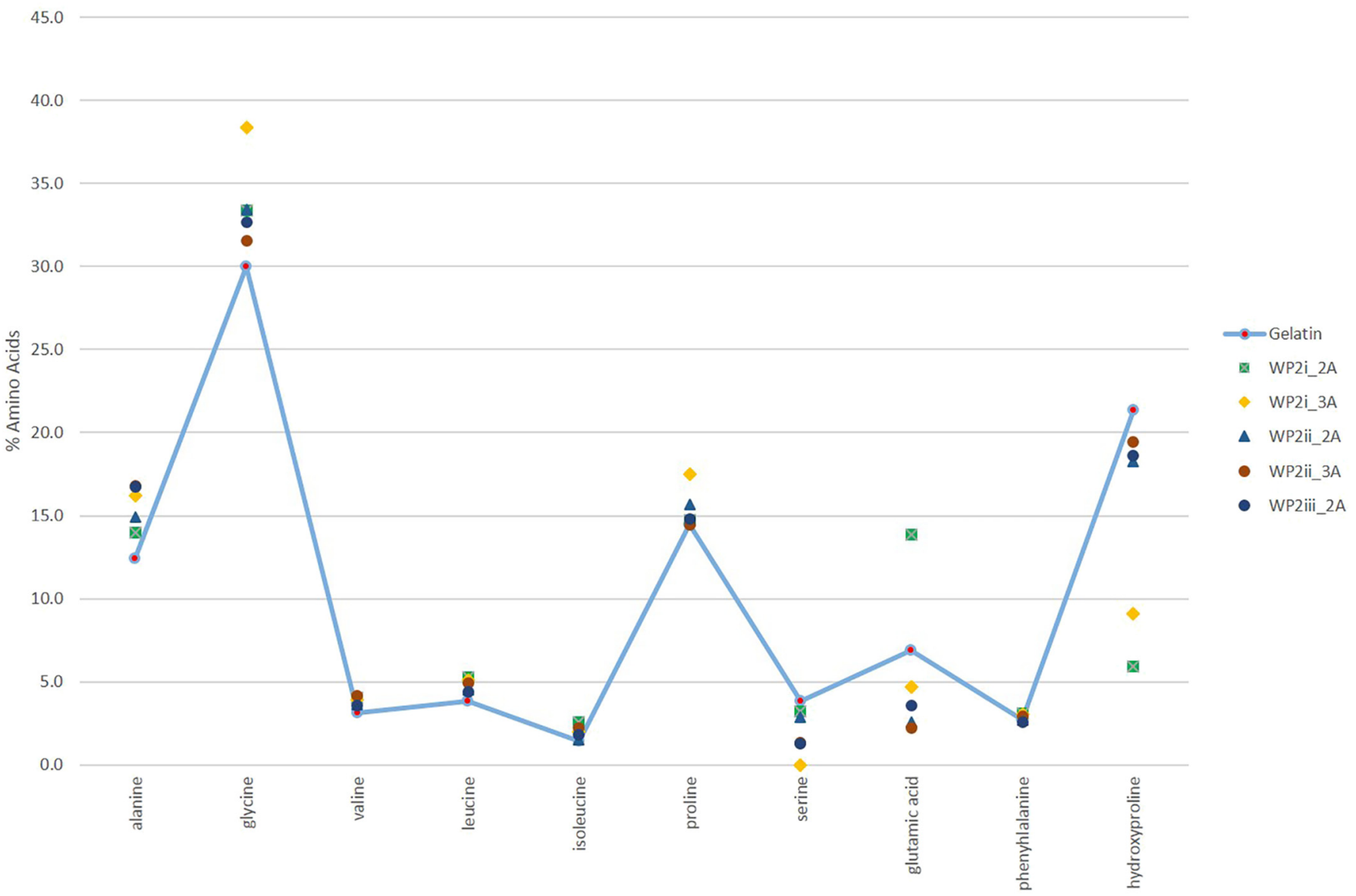

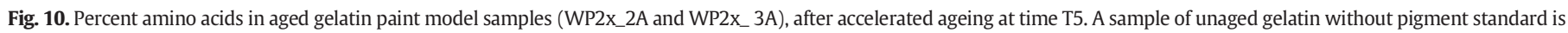
included for comparison. In all aged paint samples there is an increase in alanine, glycine, and proline, with a decrease in hydroxyproline.

reduction of hydroxyproline and changes in relative amounts of the other amino acids, all of the samples tested showed a good match to gelatin or egg. Moreover, the presence of new unknown degradation products in the chromatograms needs further research for their recognition.

In archaeological wall paintings, the protein concentrations in the analysed paint samples are often lower than $1 \%$ by weight of amino acids. In the present study it has been attested that for the samples taken on the aged (T5) paint models, with lime water and a low organic binder content, either egg-based or gelatin-based (e.g. WP1i_2A, WP1i_3A WP2i 2A, WP2i_3A), the amino acids content was between 0.2 and $0.8 \%$. Amino acids will further degrade with ageing, transforming into unknown byproducts, making the identification of proteinaceous binding media increasingly difficult.

Exploring the EGA/MS pyrolysis analytical data, at a macromolecular level, the paint model systems analysed after accelerated ageing showed a behaviour that is attested in archaeological paint samples: the older and the more degraded the samples are, the higher the temperature at which the polypeptide chain is thermally degraded, and the smaller the relative amounts of DKPs that are formed upon ageing. It has been proposed that the higher the temperature at which aromatic molecules are evolved and the smaller the relative amount of DKPs evolved, the older or more degraded the sample would be, hypothesising that DKPS cannot be produced upon ageing when the protein is highly aggregated and cross-linked [16].
Therefore, in extensively aged samples, the identification of the original binder is not possible by using analytical pyrolysis, as specific DKPs are not present anymore, and the pyrolytic profile of aromatic compounds loses its specificity. On the other hand, when highly thermally stable proteins are obtained, they show very little solubility, challenging also GC-MS approaches [16]. The data here presented for gelatin-based paints suggest that further ageing would lead to those conditions, in which the protein becomes extremely thermally stable, as observed in some of most degraded samples presented in the literature [16], indicating that the protein identification might become extremely complex, if possible at all with classical approaches.

However, it has been shown in this study that things stand differently in egg yolk containing paints. Hexadecanonitrile and octadecanenitrile, which we identify as result of the thermal degradation of the product of a strong chemical interaction between the carbonyl moieties of egg lipids and the primary amine group of Lysine and Arginine, the lipoproteins of egg yolk, were still clearly present in the EGA/MS profiles of the most degraded samples analysed.

This would indicate that egg (yolk or whole egg) could be identified even in very aged and degraded samples by using analytical pyrolysis, despite the absence of DKPs and other characteristic compounds such as indole, benzeneacetonitrile or methyl-phenol in their pyrolytic profiles, based on the detection of hexadecanonitrile and octadecanenitrile. Interestingly, egg yolk showed a similar ageing behaviour for all the pigments analysed while other proteinaceous materials (gelatin) seem to 

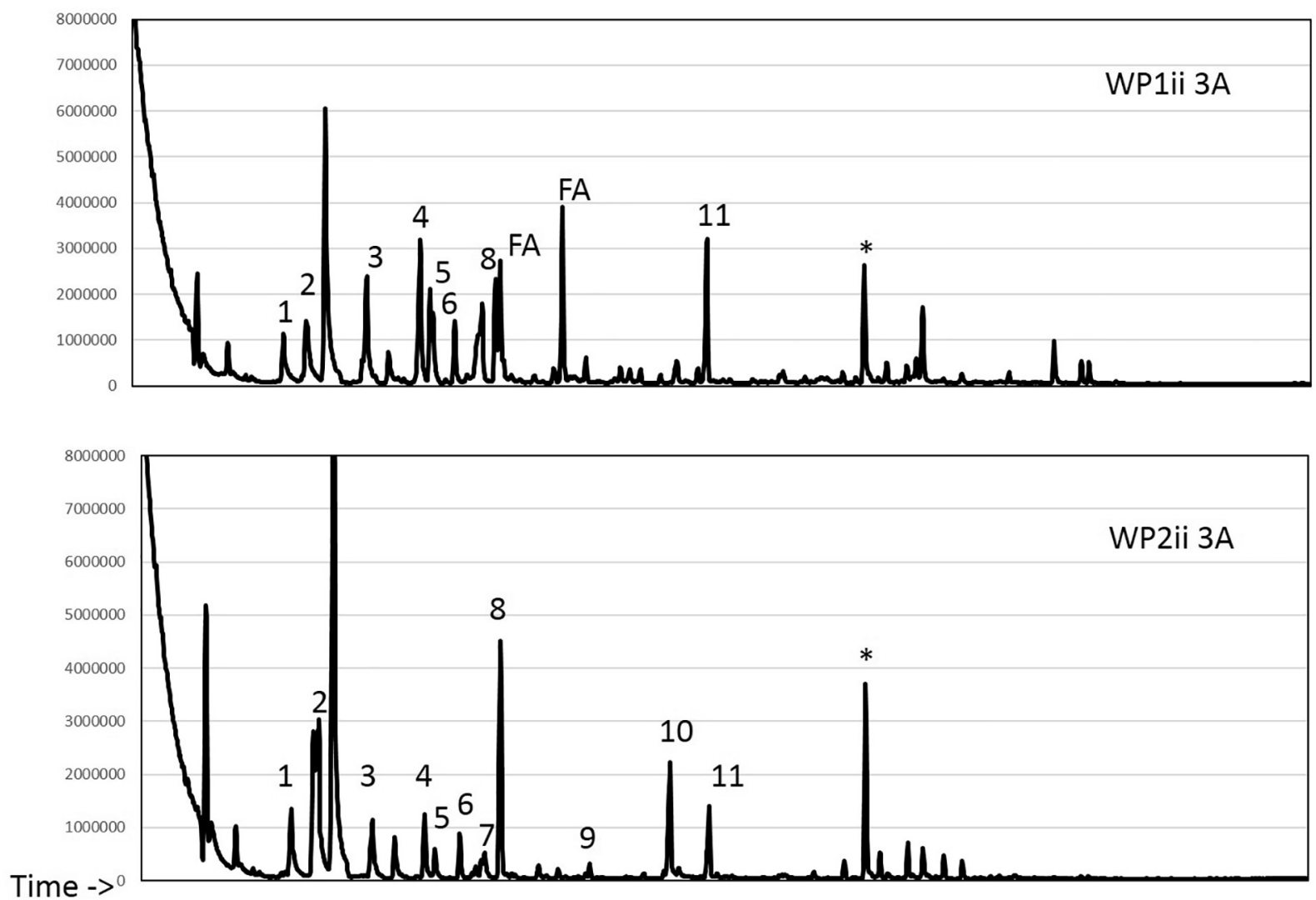

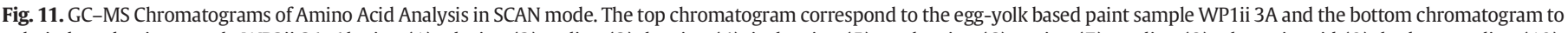

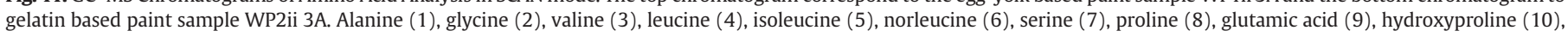
phenylalanine (11). FA = fatty acid. The unidentified peak labeled with * is attributed to contamination, as it is present in the limewater paint (WP0 3 ) as well (results not shown).

behave differently on the basis of the pigment admixed, meaning that there is a role played in the ageing of the paint system by the pigment and not solely by the lime mortar.

\subsubsection{Identification of degradation products or mechanisms}

One of the principal aims of the research was to elucidate degradation mechanisms and to define alteration products that could be considered as markers of original substances in the paint system. To this aim, the contribution of micro FTIR-ATR mapping in the layer-resolved molecular analysis of degradation markers following gradual stages of ageing was proved essential to advance our understanding of possible mechanisms happening through the paint stratigraphy over time.

The study of cross-sections of the paint models with egg-yolk binder and $\mathrm{Fe} / \mathrm{Pb}$ red pigments (WP1 (ii, iii) $(2,3)$ ) allowed to confirm that the degradation of egg tempera paint systems due to ageing may be mainly related to the fatty components in the yolk with the formation of free fatty acids groups. As in many studies in literature, also in the present study, it was possible to identify the free fatty acids and the carboxylate groups in the egg yolk/red ochre paint layers (samples WP1 (ii, iii) 2A) correlated with the broadening and the reduced intensity of the carbonyl band, which is probably linked to triglyceride hydrolysis processes. Importantly, as observed in the red ochre paint layer of the examined models, although the mechanism seems to be triggered by the presence of the red ochre's iron ions, which act in favour of the hydrolysis process, the identified carboxylate compounds were ascribed to calcium carboxylates. This finding may be explained by an enrichment of calcium carbonate attested in the paint layers, which is possibly related to the ongoing carbonation process of lime during ageing, as the paint models were prepared when the lime ground was merely dried. Additionally, the formation of calcium oxalates, also observed within the paint layer of the same cross-sections, was assigned as final product of the degradation mechanism starting from the autoxidation of the fatty content of the binding medium (WP1 - egg yolk). The higher concentration of oxalates located in the upper/superficial part of the paint layer confirms common findings demonstrated in several studies in ancient wall paintings. This distribution is probably induced by exposure of the paint layer rich in binder to (artificial) ageing.

In the case of models prepared with a second red lead paint layer (WP1ii_3A), the reactivity of lead ions to form metal carboxylates in paints with lipidic binders was confirmed. In parallel, the upwards mobility of calcium salts and the final formation of calcium oxalates located within the uppermost red lead layer, was also attested in these bilayered (red ochre/red lead) stratigraphy.

In the samples with read lead in the second paint layer, a fast (already at initial stages of ageing) and increasing with time conversion of the lead oxide into lead carbonate was identified. Although red lead does not present any characteristic bands in the Mid IR range, its degradation was followed in the FTIR spectra by the progressive formation of basic lead carbonate upon ageing. A significant decomposition of the read lead pigment has been also evidenced through the comparative diffuse reflectance measurements in the visible range acquired on the paint surface of the models with all the examined binders.

In the case of gelatin-based paint layers (WP2ii_3A), despite the significant conversion of lead oxide to (basic) lead carbonate attested in the FTIR measurements, a relative stability of the proteinaceous binder was observed. The examination of these samples allowed also for a preliminary statement referring to the attribution of calcium oxalates to specific substances present in the paint system. The microFTIR-ATR mapping analysis of equivalent sample typologies, presenting one (WP2iii_2A) or two (WP2ii_3A) paint layers but containing gelatin instead of egg binder, demonstrated that after ageing there was not any significant degradation of the spectroscopic profile of Mid-IR protein 
bands (amide I and II). Consequently, the absence of any oxalates in all the gelatin-based samples presumably dissociates the formation of oxalates from a non lipidic binder and confirms what was already observed, that the lipidic fraction in the binder may encourage the formation of metal oxalates. However, further studies will be aimed at validating these results also on different types of lipidic or non-fatty binders, submitted to different weathering treatments.

\section{Conclusions}

The proposed in this study non-invasive and microsampling methodology was optimized on well-defined models that have been designed to simulate different painting techniques with limewater and organic binders, typical of ancient wall paintings.

A first comparative evaluation and complementary interpretation of the results was approved on the study of model paint systems with three proteinaceous binders, egg-yolk, gelatin and egg-white based. Furthermore, the outcomes of the study up to date needs to be further evaluated taking into account different aspects. In particular, the continuance of the project will allow the expansion of our data and contribute to:

- Confirm, adjust or refine the results on the role of the reactivity of the metal ions of the pigment in the degradation of the system pigment - binding medium -lime ground with the examination of the paint model systems with two additional pigments, malachite $(\mathrm{Cu})$ and Carbon black.

- Examine the impact of the ageing in the degradation of the paint system in the case of different binding media. At a next step, polysaccharide binders will be studied, with the analysis of paint models prepared with Arabic and Tragacanth gums. At a final step, comparative evaluation of the results on proteinaceous and polysaccharide binding media will follow.

- Explore possible evolution of the degradation mechanisms with the continuation of the ageing protocol to be applied for additional time intervals.

Supplementary data to this article can be found online at https://doi. org/10.1016/j.microc.2018.03.007.

\section{Acknowledgments}

This work was developed in the framework of the Joint Research activities within the IPERION-CH project (Integrated Platform for the European Research Infrastructure ON Cultural Heritage) which is funded by the European Commission, H2020-INFRAIA-2014-2015, under Grant No. 654028.

Special thanks are due to Panagiotis Angelidis, Conservator specialized in Ancient Wall Paintings for his invaluable assistance in the preparation of the paint models on the lime-based mortar support.

\section{References}

[1] S. Sfarra, C. Ibarra-Castanedo, M. Tortora, L. Arrizza, G. Cerichelli, I. Nardi, X. Maldague, Diagnostics of wall paintings: a smart and reliable approach, J. Cult. Herit. 18 (2016) 229-241.

[2] I. Holclajtner-Antunović, M. Stojanović-Marić, D. Bajuk-Bogdanović, R. Žikić, S. Uskoković-Marković, Multi-analytical study of techniques and palettes of wall paintings of the monastery of Žiča, Serbia, Spectrochim. Acta A Mol. Biomol. Spectrosc. 156 (2016) 78-88.

[3] Francesca Piqué, Giovanni Verri, Getty Conservation Institute (Eds.),Organic Materials in Wall Paintings, 2015 (Project Report).

[4] H. Brecoulaki, A. Andreotti, I. Bonaduce, M.P. Colombini, A. Lluveras, Characterization of organic media in the wall-paintings of the "Palace of Nestor" at Pylos, Greece: evidence for a secco painting techniques in the Bronze Age, J. Archaeol. Sci. 39 (2012) 2866-2876.

[5] J. Cuní, What do we know of Roman wall painting technique? Potential confounding factors in ancient paint media analysis, Herit. Sci. 4 (2016) 44.
[6] L. Ghezzi, C. Duce, L. Bernazzani, E. Bramanti, M.P. Colombini, M.R. Tiné, I. Bonaduce, Interactions between inorganic pigments and rabbit skin glue in reference paint reconstructions, J. Therm. Anal. Calorim. 122 (2015) 315, https://doi.org/10.1007/ s10973-015-4759-x.

[7] S. Sotiropoulou, Z.E. Papliaka, L. Vaccari, MicroFTIR imaging for the investigation of deteriorated organic binders in wall painting stratigraphies of different techniques and periods, Microchem. J. 124 (2015) 559-567.

[8] S. Prati, G. Sciutto, E. Catelli, A. Ashashina, R. Mazzeo, Development of innovative embedding procedures for the analyses of paint cross sections in ATR FITR microscopy, Anal. Bioanal. Chem. 405 (2-3) (2013) 895-905.

[9] A. Lluveras, I. Bonaduce, A. Andreotti, M.P. Colombini, GC/MS analytical procedure for the characterization of glycerolipids, natural waxes, terpenoid resins, proteinaceous and polysaccharide materials in the same paint microsample avoiding interferences from inorganic media, Anal. Chem. 82 (1) (2010) 376-386.

[10] N. Salvadò, S. Buttí, J. Nicholson, H. Emerich, A. Labrador, T. Pradell, Identification of reaction compounds in micrometric layers from gothic paintings using combined SRXRD and SR-FTIR, Talanta 79 (2009) 419-428.

[11] N. Salvadó, S. Butí, M. Cotte, G. Cinque, T. Pradell, Shades of green in 15th century paintings: combined microanalysis of the materials using synchrotron radiation XRD, FTIR and XRF, Appl. Phys. A Mater. Sci. Process. 111 (2013) 47-57.

[12] A. Nevin, J.L. Melia, I. Osticioli, G. Gautier, M.P. Colombini, The identification of copper oxalates in a 16th century Cypriot exterior wall painting using micro FTIR microRaman spectroscopy and Gas Chromatography-Mass Spectrometry, J. Cult. Herit. 9 (2008) 154-161.

[13] D. Fabbri, A. Adamiano, G. Falini, R. De Marco, I. Mancini, Analytical pyrolysis of dipeptides containing proline and amino acids with polar side chains. Novel 2,5diketopiperazine markers in the pyrolysates of proteins, J. Anal. Appl. Pyrolysis 95 (2012) 145-155.

[14] T.F.M. Oudemans, G.B. Eijkel, J.J. Boon, Identifying biomolecular origins of solid organic residues preserved on Iron Age Pottery using DTMS and MVA, J. Archaeol. Sci. 34 (2007) 173-193.

[15] A. Adamiano, D. Fabbri, G. Falini, M.G. Belcastro, A complementary approach using analytical pyrolysis to evaluate collagen degradation and mineral fossilisation in archaeological bones: the case study of Vicenne-Campochiaro necropolis (Italy), J. Anal. Appl. Pyrolysis 100 (2013) 173-180.

[16] S. Orsini, F. Parlanti, I. Bonaduce, Analytical pyrolysis of proteins in samples from artistic and archaeological objects, J. Anal. Appl. Pyrolysis 124 (2017) 643-657.

[17] M. Schilling, H. Khanjian, Gas chromatographic analysis of amino acids as ethy chloroformate derivatives II. Effects of pigments and accelerated aging on the identification of proteinaceous binding media, J. Am. Inst. Conserv. 35 (1996) 123-144.

[18] R.J. Gettens, G.L. Stout, Painting Materials: A Short Encyclopaedia, Dover Publications Inc., 1966

[19] S. Aze, J.-M. Vallet, V. Detalle, O. Grauby, A. Baronnet, Chromatic alterations of red lead pigments in artworks: a review, Phase Trans. 81 (2-3) (2008) 145-154.

[20] S. Aze, J.-M. Vallet, A. Baronnet, O. Grauby, The fading of red lead pigment in wall paintings: tracking the physico-chemical transformations by means of complementary micro-analysis techniques, Eur. J. Mineral. 18 (2006) 835-843.

[21] J. Liang, X. Wan, C. Li, J. Li, Q. Liu, Q. Cao, Construction of spectral discoloration model for red lead pigment by aging test and simulating degradation experiment, J. Spectrosc. 2016 (2016), 3517496. https://doi.org/10.1155/2016/3517496, (11 pages).

[22] Sister Daniilia, E. Minopoulou, A study of smalt and red lead discolouration in Antiphonitis wall paintings in Cyprus, Appl. Phys. A Mater. Sci. Process. 96 (3) (2009) 701-711.

[23] R. Mazzeo, S. Prati, M. Quaranta, E. Joseph, E. Kendix, M. Galeotti, Attenuated tota reflection micro FTIR characterisation of pigment-binder interaction in reconstructed paint films, Anal. Bioanal. Chem. 392 (1-2) (2008) 65-76.

[24] J.J. Hermans, K. Keune, A. van Loon, R.W. Corkery, P.D. Iedema, Ionomer-like structure in mature oil paint binding media, RSC Adv. 6 (96) (2016) 93363-93369.

[25] J. Van der Weerd, A. van Loon, J.J. Boon, FTIR studies of the effects of pigments on the aging of oil, Stud. Conserv. 50 (1) (2005) 3-22.

[26] Gary C. Jones, B. Jackson, Infrared Transmission Spectra of Carbonate Minerals, Springer Science \& Business Media, 2012.

[27] J.S. Mills, R. White, The Organic Chemistry of Museum Objects, 2nd edition Butterworth Heinemann, Oxford, 1994.

[28] I. Bonaduce, A. Andreotti, Py-GC/MS of Organic Paint Binders, John Wiley Nd Sons, Ltd., Chichester, 2009.

[29] J.D.J. van den Berg, N.D. Vermist, L. Carlyle, M. Holčapek, J.J. Boon, Effects of traditional processing methods of linseed oil on the composition of its triacylglycerols, J. Sep. Sci. 27 (2004) 181-199.

[30] I. Bonaduce, J.J. Boon, An integrated mass spectrometric and molecular imaging analytical approach to identify and localise constituents in paintings applied to gilded multilayer structures from 14th to 16 th C works of art, in: M.P. Colombini, L. Tassi (Eds.), New Trends in Analytical, Environmental and Cultural Heritage Chemistry, Research Signpost, Transworld Research Network, Kerala, India 2008, pp. 389-423.

[31] I. Bonaduce, M.P. Colombini, Gas chromatography/mass spectrometry for the characterization of organic materials in frescoes of the Momumental Cemetery of Pisa (Italy), Rapid Commun. Mass Spectrom. 17 (2003) 2523-2527.

[32] K. Uchida, Y. Kato, S. Kawakishi, Metal-catalyzed oxidative degradation of collagen, J Agric. Food Chem. 40 (1992) 9-12.

[33] P. Richardin, C. Chahine, S. Copy, F. Saltron, S. Bonnassies-Termes, Gas chromatography-mass spectrometry identification of collagen breakdown products in naturally and artificially aged leathers, J. Am. Leather Chem. Assoc. 91 (1) (1996) 2-17.

[34] J.R. Clamp, L. Hough, The periodate oxidation of amino acids with reference to studies on glycoproteins, Biochem. J. 94 (1) (1965) 17-24. 